OPEN ACCESS

Edited by:

Hanting Zhang,

West Virginia University, United States

Reviewed by:

Chuang Wang,

Ningbo University, China

Enrico Sanna,

University of Cagliari, Italy

Yan-Xue Xue,

Peking University, China Jianyang $\mathrm{Du}$,

University of Toledo, United States

${ }^{*}$ Correspondence:

Wen-Hua Zhang

whzhang@ncu.edu.cn

Bing-Xing Pan

panbingxing@ncu.edu.cn

${ }^{\dagger}$ These authors have contributed equally to this work

Specialty section:

This article was submitted to

Neuropharmacology,

a section of the journal

Frontiers in Neuroscience

Received: 25 December 2019

Accepted: 16 March 2020

Published: 17 April 2020

Citation:

Pan H-Q, Zhang W-H, Liao C-Z, He Y, Xiao Z-M, Qin X, Liu W-Z, Wang N, Zou J-X, Liu X-X and

Pan B-X (2020) Chronic Stress Oppositely Regulates Tonic Inhibition

in Thy1-Expressing

and Non-expressing Neurons

in Amygdala. Front. Neurosci. 14:299

doi: 10.3389/fnins.2020.00299

\section{Chronic Stress Oppositely Regulates Tonic Inhibition in Thy1-Expressing and Non-expressing Neurons in Amygdala}

\begin{abstract}
Han-Qing Pan ${ }^{1,2 \dagger}$, Wen-Hua Zhang ${ }^{1,2 *}$, Cai-Zhi Liao ${ }^{1,2}$, Ye He ${ }^{3}$, Zhi-Ming Xiao², Xia Qin 1,2, Wei-Zhu Liu'1,2, Na Wang ${ }^{4}$, Jia-Xin Zou ${ }^{1,2}$, Xiao-Xuan Liu' ${ }^{1,2}$ and Bing-Xing Pan ${ }^{1,2 *}$

${ }^{1}$ Department of Biological Science, School of Life Sciences, Nanchang University, Nanchang, China, ${ }^{2}$ Laboratory of Fear and Anxiety Disorders, Institutes of Life Science, Nanchang University, Nanchang, China, ${ }^{3}$ Center for Medical Experiments, Nanchang University, Nanchang, China, ${ }^{4}$ Department of Physiology, Mudanjiang Medical University, Mudanjiang, China
\end{abstract}

Chronic or prolonged exposure to stress ranks among the most important socioenvironmental factors contributing to the development of neuropsychiatric diseases, a process generally associated with loss of inhibitory tone in amygdala. Recent studies have identified distinct neuronal circuits within the basolateral amygdala (BLA) engaged in different emotional processes. However, the potential circuit involved in stress-induced dysregulation of inhibitory tones in BLA remains elusive. Here, a transgenic mouse model expressing yellow fluorescent protein under control of the Thy1 promoter was used to differentiate subpopulations of projection neurons (PNs) within the BLA. We observed that the tonic inhibition in amygdala neurons expressing and not expressing Thy1 (Thy1+/-) was oppositely regulated by chronic social defeat stress (CSDS). In unstressed control mice, the tonic inhibitory currents were significantly stronger in Thy1- PNs than their Thy1+ counterparts. CSDS markedly reduced the currents in Thy1- projection neurons (PNs), but increased that in Thy1+ ones. By contrast, CSDS failed to affect both the phasic A-type $\gamma$-aminobutyric acid receptor $\left(G A B A_{A} R\right)$ currents and $G_{A B A} R$ currents in these two PN populations. Moreover, chronic corticosterone administration was sufficient to mimic the effect of CSDS on the tonic inhibition of Thy1+ and Thy1-PNs. As a consequence, the suppression of tonic $\mathrm{GABA}_{A} \mathrm{R}$ currents on the excitability of Thy1- PNs was weakened by CSDS, but enhanced in Thy1+ PNs. The differential regulation of chronic stress on the tonic inhibition in Thy1+ and Thy1- neurons may orchestrate cell-specific adaptation of amygdala neurons to chronic stress.

Keywords: chronic stress, amygdala, tonic inhibition, Thy1, neuronal excitability, corticosterone

\section{INTRODUCTION}

Exposure to extreme or prolonged stress leads to a spectrum of brain and behavior abnormalities and is associated with the onset and exacerbation of various neuropsychiatric diseases including anxiety disorder and depression (de Kloet et al., 2005; McEwen, 2007). Amygdala, a diamondshaped region located deep inside the temporal lobe, is critically engaged in encoding external information with distinct valence (Janak and Tye, 2015). Accumulating evidence in past decades has identified amygdala as a primary target of stress and a key mediator of stress adversity in brain. For example, chronic stress causes considerable structural and functional remodeling of amygdala 
neurons (Vyas et al., 2002; Zhang J.Y. et al., 2019), resulting in persistent and excessive activation of amygdala (Rosenkranz et al., 2010; Zhang W.H. et al., 2019) and contributing to pathogenesis of stress-related mental disorders (Qin et al., 2015; Zhou et al., 2019).

Under resting state, amygdala has a highly inhibitory tone, which distinguishes it from its proximal regions (LeDoux, 2007). This provides a brake for amygdala to limit its activation by the neutral information in the environment, thus avoiding excessive or inappropriate expression of emotion (Quirk and Gehlert, 2003; Jie et al., 2018). However, under some adverse conditions such as prolonged exposure to stressful events, the high inhibitory tone is removed, leading to persistent and excessive activation of amygdala (Manzanares et al., 2005; Liu et al., 2014). We have recently observed that the impaired inhibition in amygdala by chronic stress is primarily due to the loss of tonic inhibition (Liu et al., 2014), which is mediated by extrasynaptic $\mathrm{GABA}_{\mathrm{A}} \mathrm{Rs}$, rather than the phasic inhibition by synaptic $\mathrm{GABA}_{\mathrm{A}}$ Rs. Notably, both preclinical and clinical evidence has demonstrated that GABAergic disinhibition is highly linked to the pathogenesis of multiple neuropsychiatric diseases (Brambilla et al., 2003; Bohnsack et al., 2018; Zhang et al., 2018) and the therapeutic effect of many anxiolytic agents acts at least partially through augmenting GABAergic inhibition in amygdala (Nuss, 2015). Thus, understanding the precise mechanisms underlying stressinduced GABAergic disinhibition in amygdala may yield novel targets for prevention and treatment of stress-related neuropsychiatric disorders.

In recent years, evidence has been accumulated to dissect the structure and function of individual amygdala neurons at the molecular and circuit levels (Senn et al., 2014; Kim et al., 2016). Thyl is a glycophosphatidylinositol-anchored glycoprotein expressed on the cell membrane of various types of cells (Williams and Gagnon, 1982). Interestingly, Thy1 has been recently used as a neuronal marker to differentiate subpopulations of the projection neurons (PNs) in the basolateral amygdala (BLA) express Thy1, and Thy1+ and Thy1- PNs appear to be differently engaged in amygdala-related tasks (Jasnow et al., 2013; McCullough et al., 2016; Gilman et al., 2018). For example, the Thy1 + PNs in amygdala were activated during fear extinction and extinction retention, whereas the Thy1- neurons were recruited during fear expression (McCullough et al., 2016). Nonetheless, how chronic stress impacts the GABAergic signal in the two populations in amygdala is yet unknown.

To answer this question, we subjected the mice with the expression of YFP driven by the Thyl promoter to chronic social defeat stress (CSDS) from postnatal day 35 through day 45 . We observed that CSDS markedly reduced the tonic inhibitory currents in Thy1- PNs but increased those in Thy1+ PNs, with negligible influence on the phasic $\mathrm{GABA}_{\mathrm{A}} \mathrm{R}$ currents and $\mathrm{GABA}_{\mathrm{B}} \mathrm{R}$-mediated currents in both neuronal populations. The opposite influences of CSDS could be readily mimicked by chronic administration of corticosterone (CORT). As a consequence, the GABAergic suppression of the excitability of Thyl- and Thyl+ PNs was weakened and augmented by CSDS, respectively.

\section{MATERIALS AND METHODS}

\section{Animals}

Male B6.Cg-Tg (Thy1-YFP) HJrs/J (Thy1-YFP) mice and CD-1 retired breeders were used in this study. All animals were housed in a temperature-maintained, humidity-controlled colony with convenient access to food and water, and a 12:12 h/light-dark cycle (7 a.m. to 7 p.m.). All experimental procedures were approved by the Institutional Animal Care and Use Committee of Nanchang University.

\section{Chronic Social Defeat Stress}

The CSDS was performed as described previously (Golden et al., 2011). Briefly, the Thyl-YFP intruder mouse was exposed to a different aggressive resident CD-1 mouse for $5 \mathrm{~min}$ each day and lasted for 10 consecutive days. After $5 \mathrm{~min}$ of social defeat, the intruder mouse and the resident mouse were separated by a perforated acrylic plate for $24 \mathrm{~h}$ to maintain a sensory stress to the intruder mice. The control mice were housed in equivalent cages but with members of the same strain, which were changed daily.

\section{Chronic Corticosterone Administration}

Corticosterone was dissolved in $\mathrm{EtOH}$ as the stock solution and freshly prepared in drinking water every day $(\mathrm{EtOH}<1 \%$ at final concentration) and delivered in bottles, which were wrapped with silver paper to prevent from light. The vehicle-treated mice were allowed to drink water containing $1 \% 0$ ethanol. The entire procedure lasted for 10 days.

\section{Open Field Test}

Open field test (OFT; Med Associates Inc., Fairfax, VT, United States) was performed as previously described (Zhang W.H. et al., 2019). Briefly, mice were habituated in the test room for $30 \mathrm{~min}$, followed by placing mice in a square chamber $(50 \times 50 \mathrm{~cm})$ with white light. The mouse activity was monitored for $10 \mathrm{~min}$. The center square $(25 \times 25 \mathrm{~cm})$ of the chamber was defined as the center area, and the time spent in the center area and entries in the center area were assessed by the video monitoring software (SOF-842; Med Associates Inc.).

\section{Elevated Plus Maze Test}

Elevated plus maze (EPM) test was performed as previously prescribed (Zhang W.H. et al., 2019). Briefly, after a $30 \mathrm{~min}$ habituation in the behavior test room with red light, experimental mice were mildly placed in the hub area facing one of the closed arms of EPM apparatus (Med Associates Inc., St. Albans, VT, United States). Their behaviors were recorded for $10 \mathrm{~min}$ by the video tracking software (DOC-086; Med Associates Inc.). Anxiety-like behavior was measured by the time spent and the number of entries in open arms.

\section{Immunohistochemistry}

The mice were anesthetized by isoflurane, followed by perfusion with phosphate-buffered saline (PBS) and 4\% paraformaldehyde (PFA) successively to fix the tissues. The brains were then postfixed in $4 \%$ PFA for $24 \mathrm{~h}$. Subsequently, the brains were 
moved to the chamber containing PBS, and $40 \mu \mathrm{m}$ slices including amygdala were sectioned by tissue slicer (VT $1000 \mathrm{~S}$ Vibratome; Leica Microsystems, Wetzlar, Germany) and stored in Section Storage Solution (FD NeuroTechologies Inc., Columbia, MD, United States).

The brain slices were rinsed in PBS $(4 \times 10 \mathrm{~min})$ and then transferred to blocking buffer (PBS with $0.1 \%$ Triton X-100 containing $10 \%$ donkey serum) for $2 \mathrm{~h}$ at room temperature. Then, the slices were incubated overnight at $4^{\circ} \mathrm{C}$ with primer antibody against CaMKII $\alpha$ (goat polyclonal antibody, 1:500; Abcam, Cambridge, United Kingdom); after that, three times rinses in PBS with $0.1 \%$ Triton X-100 before incubation with second antibody at room temperature for $2 \mathrm{~h}$ were conducted. Subsequent to three times washes, the slices were paved on the microslides and mounted with Fluoromount Aqueous Mounting Medium (Sigma-Aldrich, St. Louis, MO, United States). The images were taken by a confocal laser-scanning microscopy (Olympus FV1000; Olympus Corp., Tokyo, Japan) and processed by Olympus Fluoview (Olympus Corp.).

\section{Electrophysiological Recording}

The in vitro electrophysiological recordings were performed as previously described (Liu et al., 2014). Briefly, 1 day after the last episode of CSDS or chronic corticosterone administration, the mice were anesthetized with isoflurane and then sacrificed by decapitation. Brains were then removed immediately to icecold oxygenated $\left(95 \% \mathrm{O}_{2} / 5 \% \mathrm{CO}_{2}\right)$ partial sucrose artificial cerebrospinal fluid (ACSF) containing $80 \mathrm{mM} \mathrm{NaCl}, 3.5 \mathrm{mM}$ $\mathrm{KCl}, 4.5 \mathrm{mM} \mathrm{MgSO}_{4}, 0.5 \mathrm{mM} \mathrm{CaCl}_{2}, 1.25 \mathrm{mM} \mathrm{NaH}_{2} \mathrm{PO}_{4} \cdot 2 \mathrm{H}_{2} \mathrm{O}$, $25 \mathrm{mM} \mathrm{NaHCO}_{3}, 10 \mathrm{mM}$ glucose, and $90 \mathrm{mM}$ sucrose $(\mathrm{pH}$, 7.3-7.4). The brain slices containing BLA of $320 \mu \mathrm{m}$ were cut and collected by using the tissue slicer (VT 1000S Vibratome; Leica Microsystems) mentioned previously (Song et al., 2017) and then transferred to preheated normal ACSF containing $124 \mathrm{mM}$ $\mathrm{NaCl}, 2.5 \mathrm{mM} \mathrm{KCl}, 1 \mathrm{mM} \mathrm{MgSO}, 2.5 \mathrm{mM} \mathrm{CaCl}_{2}, 10 \mathrm{mM}$ glucose, and $22 \mathrm{mM} \mathrm{NaHCO}_{3}$ at $35^{\circ} \mathrm{C}$ for $30 \mathrm{~min}$. After that, the slices were maintained at room temperature at least $1 \mathrm{~h}$ before recording. Slices were moved to the recording chamber and perfused with ACSF at the rate of $2 \mathrm{~mL} / \mathrm{min}$. The temperature was kept at $30^{\circ} \mathrm{C} \pm 1^{\circ} \mathrm{C}$ using temperature controller (TC324B; Warner Instrument Co., Hamden, CT, United States). Whole-cell patch clamp was performed in all electrophysiological recordings. Signals were amplified and digitized by using Axon 700B Amplifier and Digidata 1440A (Molecular Device, San Jose, CA, United States) digital analog convertor, respectively. To record GABAergic signal, the recording pipettes were prepared by Sutter P97 horizontal puller and filled with $100 \mathrm{mM} \mathrm{CsCl}$, $30 \mathrm{mM}$ Cs-methane sulphonate, $5 \mathrm{mM} \mathrm{KCl}, 2 \mathrm{mM} \mathrm{MgCl}_{2}, 10 \mathrm{mM}$ HEPES, 0.2 mM EGTA, 2 mM ATP-Mg, and 0.1 mM GTP-Na; the $\mathrm{pH}$ was adjusted to 7.3-7.4 with $\mathrm{CsOH}$ and osmolarity to 290 mOsm with sucrose. To record $\mathrm{GABA}_{\mathrm{B}} \mathrm{R}$ currents and neuronal excitability, the pipette solution was replaced by those containing $130 \mathrm{mM}$ K-gluconate, $5 \mathrm{mM} \mathrm{KCl}, 2 \mathrm{mM} \mathrm{MgCl}_{2}, 10 \mathrm{mM}$ HEPES, 0.2 mM EGTA, $2 \mathrm{mM}$ ATP-Mg, and 0.1 mM GTP-Na, adjusted the $\mathrm{pH}$ to $7.3-7.4$ with $\mathrm{KOH}$ and the osmolarity to 290 mOsm with sucrose. To record phasic and tonic $\mathrm{GABA}_{\mathrm{A}} \mathrm{R}$ currents, the membrane potential was held at $-70 \mathrm{mV}$ and
$20 \mu \mathrm{M}$ CNQX; $50 \mu \mathrm{M}$ DL-APV and $5 \mu \mathrm{M}$ CGP52432 were routinely applied in bath solution to block AMPAR, NMDAR, and $\mathrm{GABA}_{\mathrm{B}} \mathrm{R}$ currents, respectively. After the spontaneous inhibitory postsynaptic currents (sIPSCs) were collected for 2$3 \mathrm{~min}, 5 \mu \mathrm{M}$ THIP or GABA was added to ensure the activation of extrasynaptic $\mathrm{GABA}_{\mathrm{A}} \mathrm{R}$, followed by $100 \mu \mathrm{M}$ picrotoxin (PTX) to block $\mathrm{GABA}_{\mathrm{A}} \mathrm{R}$ currents. To record $\mathrm{GABA}_{\mathrm{B}} \mathrm{R}$ currents, cells were held at $-50 \mathrm{mV}$ and $20 \mu \mathrm{M}$ CNQX; $50 \mu \mathrm{M}$ DL-APV and $100 \mu \mathrm{M}$ PTX were included in ACSF to prevent the interference from the currents induced by ionotropic glutamate receptors and $\mathrm{GABA}_{\mathrm{A}} \mathrm{Rs}$. To activate $\mathrm{GABA}_{\mathrm{B}} \mathrm{R}, 10 \mu \mathrm{M}$ baclofen was added followed by $5 \mu \mathrm{M}$ CGP52432 to block GABA Gs. In experiments recording neuronal excitability, the current clamp mode was performed, and the pulsed depolarization currents with increasing amplitude at step of $50 \mathrm{pA}$ (Zhang W.H. et al., 2019) or ramped depolarization current (Qin et al., 2019; Jin et al., 2020) were injected. The pipette resistance was 3-7 M $\Omega$. Series resistance (Rs) was in the range of 10-20 M $\Omega$ and monitored throughout the experiments. If Rs changed more than $20 \%$ during recording, the data would be excluded. Data were low-pass filtered at $3 \mathrm{kHz}$ and digitized at $10 \mathrm{kHz}$.

\section{Statistics}

Data were analyzed using Student $t$ test (Figure $\mathbf{1}$ and Supplementary Figure S1) or one-way (Figure 7 and Supplementary Figure S4) or two-way (Figures 2-7 and Supplementary Figures S2, S3) analysis of variance (ANOVA) with or without repeated measures, followed by post hoc test with Bonferroni correction. As for the cumulative distribution of frequency, amplitude, rise time, and decay time of sIPSCs (Figures 3, 6 and Supplementary Figures S2, S3), these data were analyzed by Kolmogorov-Smirnov test. All statistical analyses were performed using GraphPad Prism (GraphPad Software Inc., San Diego, CA, United States). Data are presented as means \pm SEM. The threshold for statistical significance was $p<0.05$.

\section{RESULTS}

\section{CSDS Increases the Anxiety-Like Behavior in Mice}

We first used OFT and EPM to test whether the CSDS used in the present study had anxiogenic effects (Figure 1A). Relative to the unstressed controls, the CSDS mice spent less time in (unpaired $t$-test, $p<0.001$; control, $n=10$; CSDS, $n=10$; Figures 1B,C) and had less entries to (unpaired $t$-test, $p<0.001$; Figures 1B,D) the center area of open field chamber during OFT. The stressed mice also spent less time in the open arms (unpaired $t$-test, $p<0.001$; Figures 1E,F) and had less entries to these arms (unpaired $t$-test, $p<0.001$; Figures 1E,G) of EPM. Besides, no significant differences were observed in the EPM closed arms entries (unpaired t-test, $p=0.2499$; Supplementary Figure S1A), locomotion in OFT (unpaired $t$-test, $p=0.7482$; Supplementary Figure S1B), and EPM (unpaired $t$ test, $p=0.8648$; Supplementary Figure S1C) of these 
A

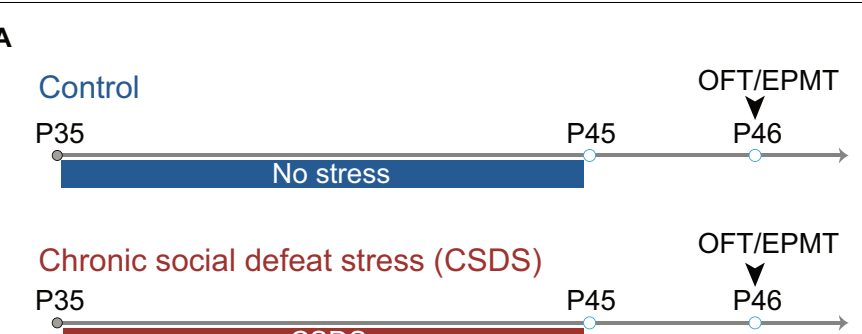

Chronic social defeat stress (CSDS) P35

CSDS
Open field test (OFT)

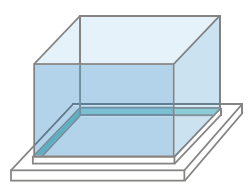

Elevated plus maze test (EPMT)

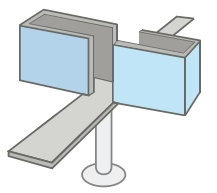

B

Control

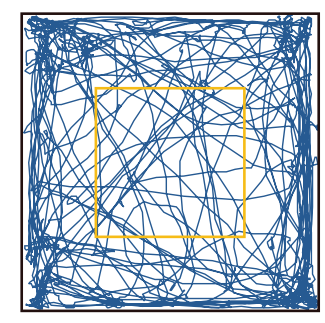

E

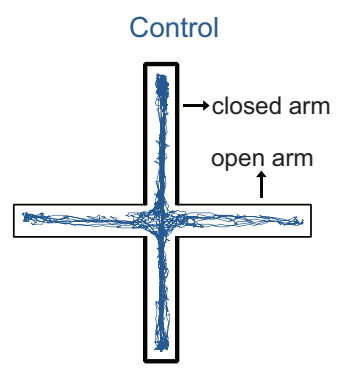

CSDS
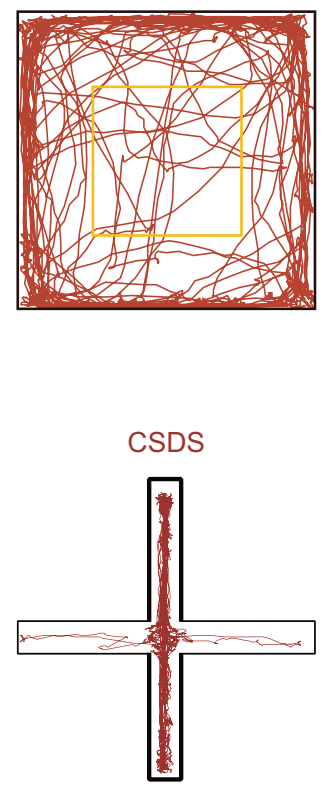

C

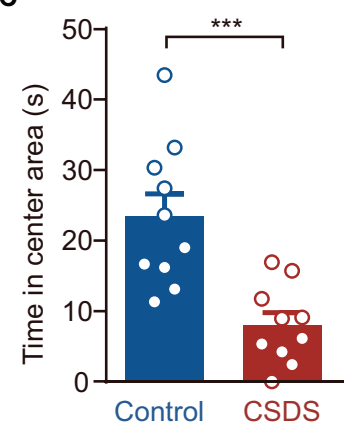

$\mathbf{F}$

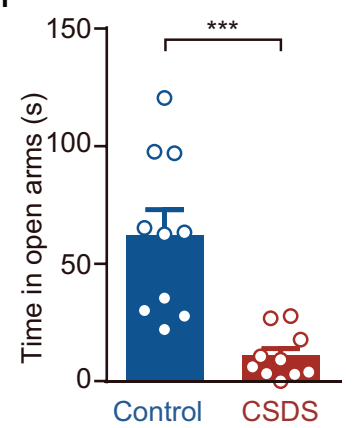

D

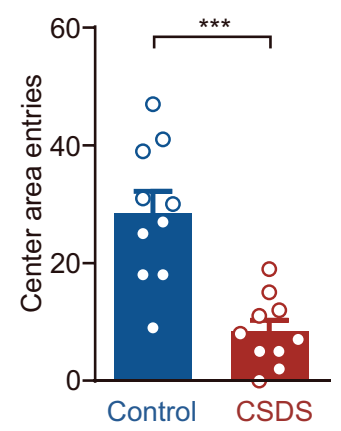

G

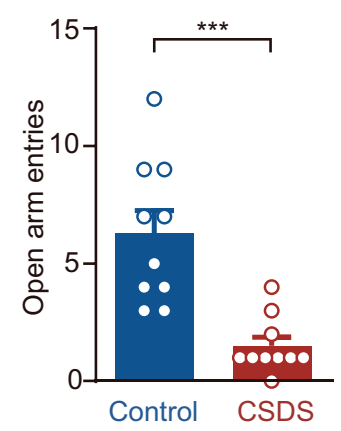

FIGURE 1 | Chronic social defeat stress (CSDS) increases anxiety-like behavior in mice. (A) Schematic showing procedures for unstressed control mice and CSDS mice. Anxiety-like behavior was measured by open field test (OFT) and elevated plus maze (EPM). (B) Representative activity tracking in the OFT in control and CSDS mice. (C) Time in center area. (D) Center area entries. (E) Representative activity tracking in the EPM in control and CSDS mice. (F) Elevated plus maze test open arm time. (G) Elevated plus maze test open arm entries. ${ }^{* \star} p<0.001$. Pooled data are presented as mean \pm SEM.

two groups. These data suggest that CSDS significantly increases the anxiety-like behavior in mice.

\section{CSDS Oppositely Regulates Tonic Inhibition in Thy1+ and Thy1- Neurons}

Next, we explored the influence of CSDS on the GABAergic currents in Thy1+ and Thy1- PNs in basal amygdala (Figure 2A). Our recent work has shown that chronic stress readily suppresses the tonic $\mathrm{GABA}_{\mathrm{A}} \mathrm{R}$ currents in the $\mathrm{PNs}$ of lateral amygdala (LA), but has little influence on the phasic $\mathrm{GABA}_{\mathrm{A}} \mathrm{R}$ currents (Liu et al., 2014). We first examined the effects of CSDS on the tonic currents induced by THIP, a super agonist of $\mathrm{GABA}_{\mathrm{A}} \mathrm{R}$, in Thyl+ and Thyl- PNs, which could be readily differentiated by the presence or absence of fluorescent labeling (Figures 2B,C). As shown in Figures 2D,E, two-way ANOVA revealed significant effect of Thyl expression $\times$ CSDS interaction
[Thy1 expression: $\left.F_{(1}, 59\right)=0.0928, p=0.7617$; CSDS: $F_{(1}$, $59)=0.1645, p=0.6866$; interaction: $\left.F_{(1}, 59\right)=14.63, p<0.001$; for Thy $1+$ neurons, $n=16$ neurons $/ 8$ control mice, $n=15$ neurons/8 CSDS mice; for Thy1- neurons, $n=15$ neurons/ 8 control mice, $n=17$ neurons/8 CSDS mice]. Post-hoc analysis revealed that in unstressed mice the tonic currents were far larger in Thy1- PNs than their Thy1+ counterparts (Thy1+ vs. Thy1-, $p=0.0328)$. However, in CSDS mice, the tonic inhibition in Thy1+ PNs was stronger than that in Thy1- PNs (Thy1+ vs. Thy1-, $p=0.0093$ ), suggesting CSDS has opposite effects on the tonic inhibition in the two populations. While markedly increasing the tonic currents in Thy1+ cells (control vs. CSDS, $p=0.0086$ ), it significantly decreased those in Thyl- ones (control vs. CSDS, $p=0.0359$ ).

To further confirm the above findings, we then resumed to test the effect of GABA, the endogenous agonist of $\mathrm{GABA}_{A} \mathrm{R}$, on the tonic inhibition onto the two neuronal populations. Similar to 
A
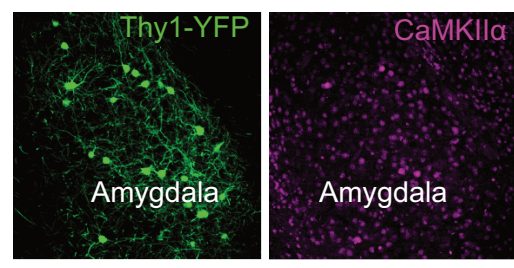

D
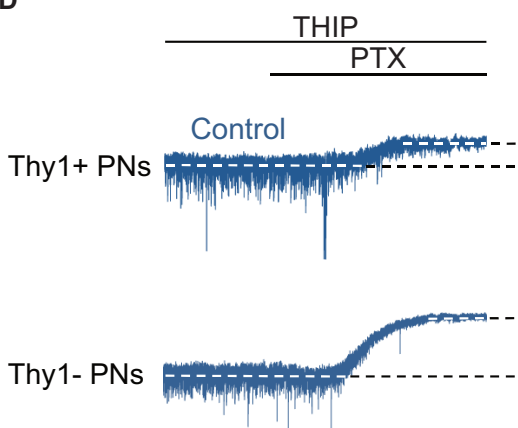

$\mathbf{F}$

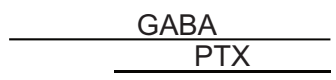

Thy1+ PNs

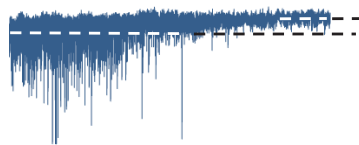

Thy1- PNs

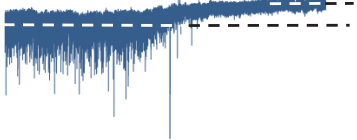

B
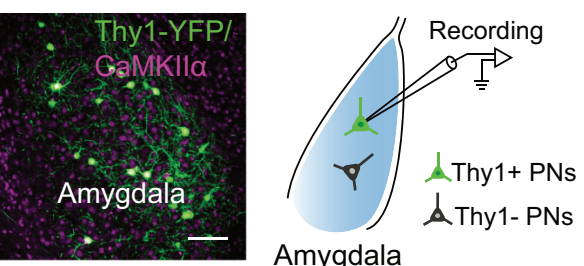

Amygdala
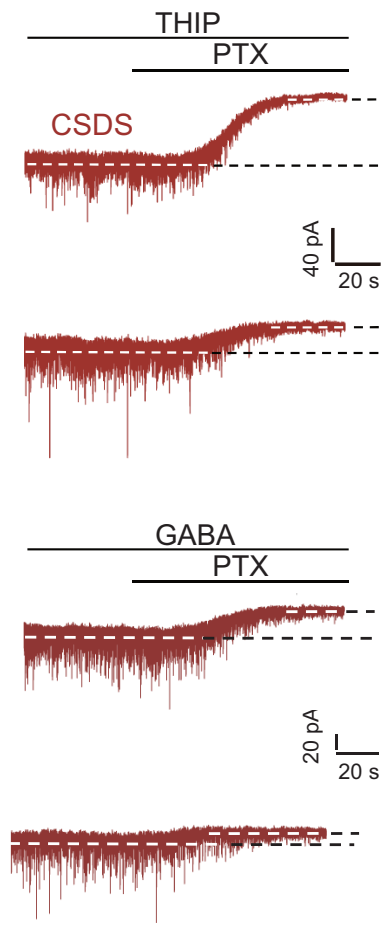

E

G c
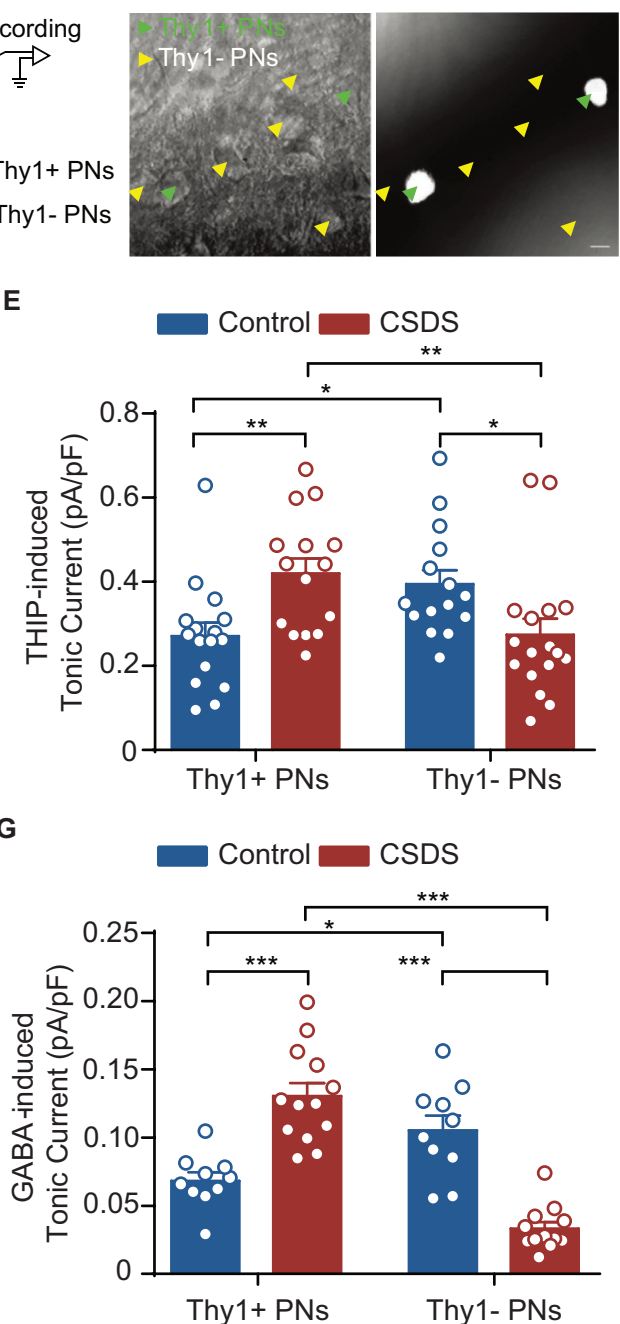

FIGURE 2 | Chronic social defeat stress increases tonic GABA $R$ currents in Thy1+ neurons, but reduces those in Thy1- neurons, in BLA. (A) Representative image showing the expression of Thy1-YFP in amygdala. CaMKll $\alpha$ was used as a marker for projection neurons (PNs). The scale bar represents 100 $\mu \mathrm{m}$. (B) Schematic showing whole-cell patch clamp recording of PNs in amygdala. (C) Infrared DIC (left) or fluorescent (right) images of Thy1+ neurons (green arrow heads) and Thy1neurons (yellow arrowheads). The scale bar represents $15 \mu \mathrm{m}$. (D) Representative traces of THIP-induced tonic GABAAR currents recorded in Thy1+ and Thy1neurons from control and CSDS mice. (E) Average of THIP-induced tonic GABA $R$ currents between Thy 1+ neurons and Thy 1- neurons. (F) Representative traces showing GABA-induced tonic GABA $R$ currents recorded in Thy1+ and Thy1- neurons from control and CSDS mice. (G) Comparison of GABA-induced tonic $\mathrm{GABA}_{\mathrm{A}} \mathrm{R}$ currents in Thy1+ and Thy1- neurons. ${ }^{*} p<0.05,{ }^{* *} p<0.01,{ }^{* \star *} p<0.001$. Pooled data are presented as mean $\pm \mathrm{SEM}$.

the results of THIP, two-way ANOVA revealed significant effect of Thyl expression $\times$ CSDS interaction [Thy1 expression: $F_{(1}$, $41)=13.00, p<0.001$; CSDS: $F_{(1,41)}=0.3664, p=0.5483$; interaction: $F_{(1,41)}=64.62, p<0.001$; for Thy1+ neurons, $n=10$ neurons $/ 5$ control mice, $n=13$ neurons $/ 6$ CSDS mice; for Thy1- neurons, $n=10$ neurons $/ 5$ control mice, $n=12$ neurons/6 CSDS mice; Figures 2F,G]. Relative to the Thy1+ PNs, GABA also evoked stronger tonic inhibitory currents in Thy1PNs in control mice (Thyl+ vs. Thy1-, $p=0.0098$ ), subsequent to CSDS, but weaker currents in CSDS mice (Thyl+ vs. Thy1-, $p<0.001)$. CSDS increased GABA-mediated tonic currents in Thy1+ PNs (control vs. CSDS, $p<0.001$ ) but decreased those in Thy1- neurons (control vs. CSDS, $p<0.001$ ).
Altogether, these data indicate the tonic inhibition is differently expressed in the two PN populations and undergoes opposite regulation by CSDS.

\section{CSDS Affects Neither Phasic GABA ${ }_{A} R$ Currents nor $\mathrm{GABA}_{B} R$ Currents in Thy1+ and Thy1- Neurons}

In addition to activating extrasynaptic $\mathrm{GABA}_{\mathrm{A}}$ Rs to generate tonic inhibition, GABA could also activate the synaptic $\mathrm{GABA}_{\mathrm{A}} \mathrm{Rs}$ to produce the phasic inhibitory currents. We next explored the effect of CSDS on the sIPSCs by synaptic $\mathrm{GABA}_{\mathrm{A}} \mathrm{Rs}$ in the two populations. As shown in Figure 3 and 
A

Thy $1+$ PNs

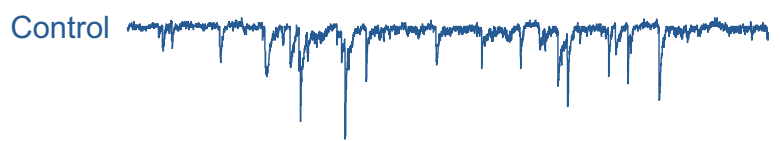

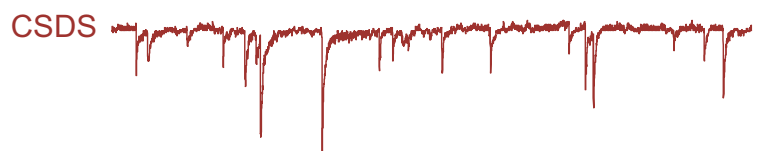

B

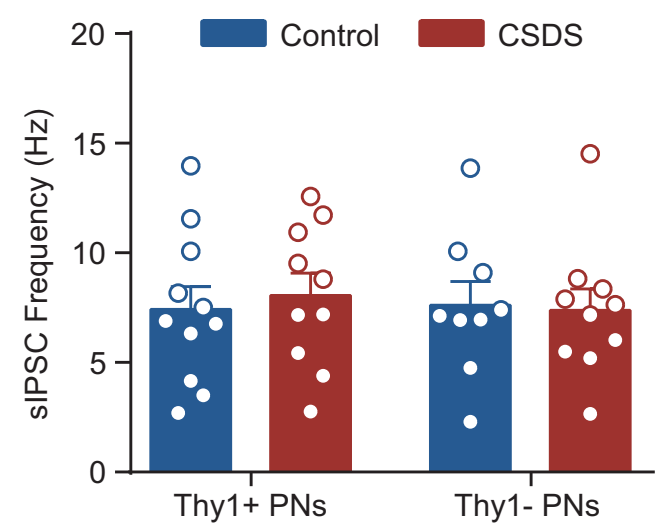

D

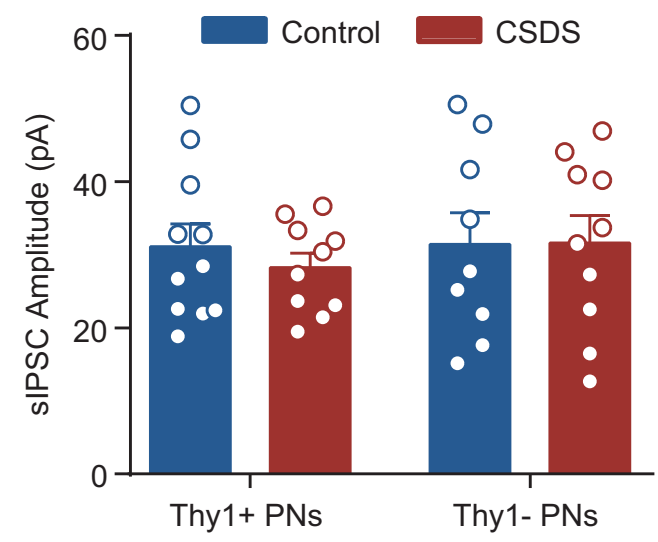

Thy1- PNs
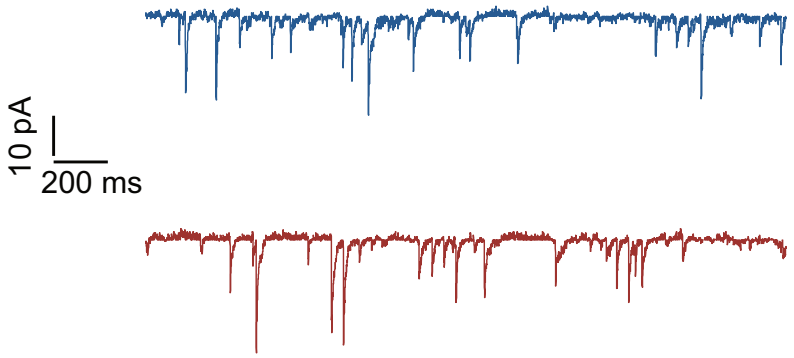

C

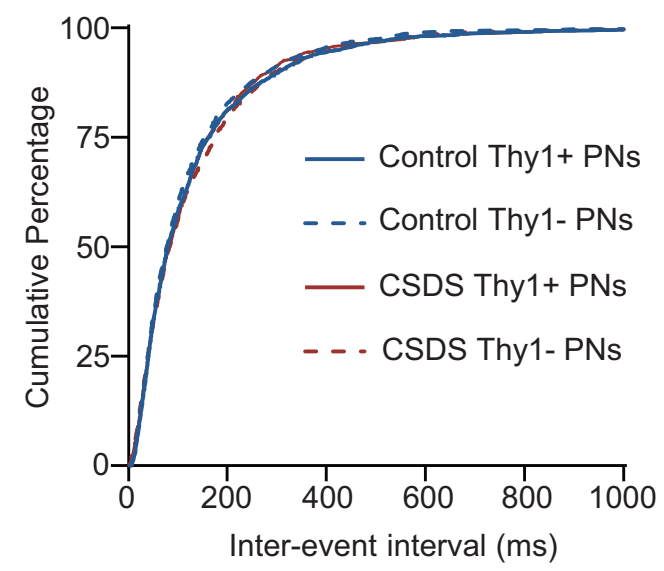

E

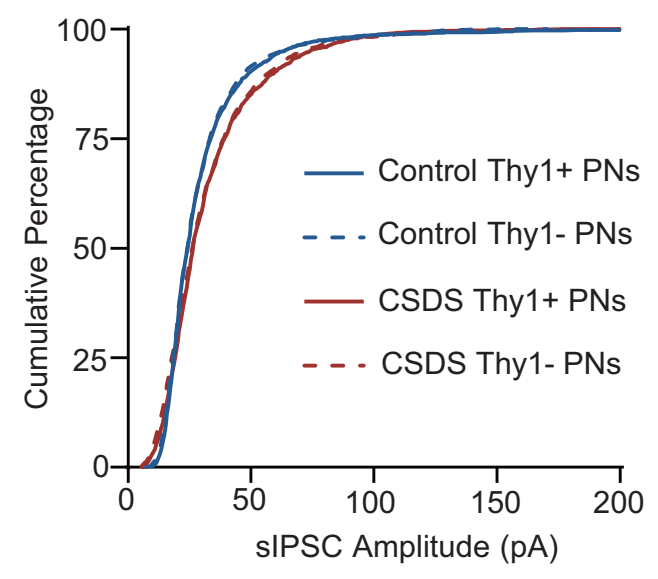

FIGURE 3 | Chronic social defeat stress has little effect on phasic GABA $R$ current in either Thy1+ or Thy1- neurons in BLA. (A) Representative traces of spontaneous inhibitory postsynaptic current (SIPSC) in Thy 1+ and Thy1- neurons from control and CSDS mice. (B) Average of sIPSC frequency. (C) Cumulative probability of interevent interval of SIPSC. (D) Average of sIPSC amplitude. (E) Cumulative probability of amplitude of sIPSC. Pooled data are presented as mean \pm SEM.

Supplementary Figure S2, both Thy1 expression and CSDS had no main effects on the mean frequencies [Thy1 expression: $F_{(1}$, 36) $=0.0374, p=0.8477$; CSDS: $F_{(1,36)}=0.0529, p=0.8194$; interaction: $F_{(1,36)}=0.1739, p=0.6792$; Thy1+ neurons, $n=11$ neurons $/ 5$ control mice, $n=10$ neurons $/ 5$ CSDS mice; Thy1- neurons, $n=9$ neurons $/ 5$ control mice, $n=10$ neurons $/ 5$ CSDS mice; Figures 3A-C], amplitudes [Thyl expression: $F_{(1}$,
$36)=0.2961, p=0.5897$; CSDS: $F_{(1,36)}=0.1555, p=0.6956$; interaction: $F_{(1,36)}=0.2092, p=0.6501$; Figures 3A,D,E], rise time [Thy1 expression: $\left.F_{(1}, 36\right)=0.0026, p=0.9597$; CSDS: $F_{(1,36)}=0.0402, p=0.8421$; interaction: $F_{(1,36)}=0.0002$, $p=0.9902$; Supplementary Figures S2A,B], or decay time [Thy1 expression: $\left.F_{(1}, 36\right)=0.0026, p=0.9594$; CSDS: $F_{(1}$, $36)=0.0039, p=0.9506$; interaction: $F_{(1,36)}=0.1984, p=0.6587$; 
Supplementary Figures S2C,D] of sIPSCs, arguing against a role of CSDS in tuning phasic $\mathrm{GABA}_{\mathrm{A}} \mathrm{R}$ currents in BLA PNs.

In neurons, GABA could also bind to the metabolic B-type GABA receptor $\left(G A B A_{B} R\right)$ to shut down the neuronal activation. We next tested whether CSDS could regulate the $G_{A B A} R$ currents in the two $\mathrm{PN}$ populations, as it did on the tonic $\mathrm{GABA}_{\mathrm{A}} \mathrm{R}$ currents (Figure 4A). Two-way ANOVA revealed significant main effect of Thyl expression but not CSDS on the $\mathrm{GABA}_{\mathrm{B}} \mathrm{R}$-mediated currents [Thy1 expression: $F_{(1,38)}=11.61$, $p=0.0016$; CSDS: $F_{(1,38)}=0.0871, p=0.7695$; interaction: $F_{(1}$, $38)=0.1723, p=0.6804$; for Thy $1+$ neurons, $n=10$ neurons $/ 5$ control mice, $n=11$ neurons/5 CSDS mice; for Thy1-neurons, $n=11$ neurons $/ 5$ control mice, $n=10$ neurons $/ 5$ CSDS mice; Figure 4B]. Post-hoc results showed that in control mice the $\mathrm{GABA}_{\mathrm{B}} \mathrm{R}$ currents were more prominent in Thy1- than those in Thyl+ PNs (Thyl+ vs. Thy1-, $p=0.0204$ ); however, in CSDS mice, there was a significant tendency that Thy1+ neurons exhibited a higher amplitude of $\mathrm{GABA}_{\mathrm{B}} \mathrm{R}$ currents (Thy1+ vs. Thy1-, $p=0.0819$ ).

\section{Chronic Corticosterone Administration Mimics the Effects of CSDS on the Tonic and Phasic GABA $R$ Currents in Thy1+ and Thy1- PNs}

Chronic stress exposure generally leads to increased secretion of glucocorticoid hormone (corticosterone in rodents), which is tightly associated with stress adversities at levels ranging from cell to behavior (Sapolsky, 2015). Chronic CORT treatment has been shown to imitate various cellular and behavioral phenotypes by chronic stress (Moda-Sava et al., 2019). To examine whether CORT was sufficient to cause distinct effect on the tonic inhibition in BLA PNs, we chronically administered the mice with CORT for a continuum of 10 days by adding CORT to the drinking water (Figure 5A). Similar to the effect of CSDS, two-way ANOVA revealed that chronic CORT administration also oppositely affected the tonic inhibition in Thyl+ and Thy1- PNs [Thy1 expression: $F_{(1,34)}=0.0330, p=0.8569$; CORT administration: $\left.F_{(1}, 34\right)=0.1239, p=0.7270$; interaction: $F_{(1,34)}=19.98, p<0.001$; for Thy1+ neurons, $n=10$ neurons/ 5 vehicle mice, $n=9$ neurons/5 CORT mice; for Thy1neurons, $n=10$ neurons $/ 5$ vehicle mice, $n=9$ neurons $/ 5$ CORT mice; Figures 5B,C]. It up-regulated the tonic $\mathrm{GABA}_{\mathrm{A}} \mathrm{R}$ currents in Thyl+ neurons (vehicle vs. CORT, $p=0.0034$ ), but down-regulated that in Thyl- neurons (vehicle vs. CORT, $p=0.0126)$. The phasic $\mathrm{GABA}_{\mathrm{A}} \mathrm{Rs}$ current, as measured by sIPSCs, remained unaltered in both populations following chronic CORT administration [frequency, Thyl expression: $\left.F_{(1}, 34\right)=0.0002, p=0.9877$; CORT administration: $F_{(1}$, $34)=0.0414, p=0.8401$; interaction: $F_{(1,34)}=0.2071$, $p=0.6520$ (Figures 6A-C); amplitude, Thyl expression: $\left.F_{(1}, 34\right)=0.2843, p=0.5974$; CORT administration: $F_{(1}$, $34)=0.1563, p=0.6951$; interaction: $F_{(1,34)}=0.2049$, $p=0.6537$ (Figures 6A,D,E); rise time, Thyl expression: $\left.F_{(1}, 34\right)=0.2862, p=0.5962$; CORT administration: $F_{(1}$, $34)=0.0007, p=0.0170$; interaction: $F_{(1,34)}=0.2545, p=0.6172$ (Supplementary Figures S3A,B); decay time, Thyl expression:
$\left.F_{(1}, 34\right)=0.0881, p=0.7684$; CORT administration: $F_{(1}$, $34)=0.2121, p=0.6480$; interaction: $F_{(1,34)}=0.2536, p=0.6178$ (Supplementary Figures S3C,D)]. These results indicate that the increased CORT secretion may contribute to the opposite regulation of CSDS on the tonic inhibition in both Thy1+ and Thy1- neurons in BLA.

\section{CSDS Oppositely Regulates the GABAergic Suppression of Neuronal Excitability in Thy1+ and Thy1- Neurons}

Persistent activation of extrasynaptic $\mathrm{GABA}_{\mathrm{A}} \mathrm{R}$ is known to suppress neuronal activity (Trujeque-Ramos et al., 2018). Given the robust but opposite effects of CSDS on the tonic $\mathrm{GABA}_{\mathrm{A}} \mathrm{R}$ currents in Thy1- and Thy1+ PNs in BLA, we speculated that CSDS might differently affect GABAergic suppression of neuronal activation in these two populations. To test this, we first injected the depolarizing current pulses with increasing intensity to the recorded neurons to evoke action potentials. Slices were then sequentially perfused with ACSF, THIP, and THIP + PTX. Somewhat surprisingly, we found that both THIP and THIP + PTX had little effect on the spike number in Thyl+ neurons from control mice [pharmacological manipulation: $\left.F_{(2}, 20\right)=1.229, p=0.3137$; depolarization steps: $\left.F_{(4}, 40\right)=48.13, p<0.001$; interaction: $F_{(8,80)}=1.375$, $p=0.2204, n=11$ neurons $/ 5$ mice; Figures 7A,B]. However, in CSDS mice, THIP markedly decreased the spike number in these cells, an effect that was completely blocked by subsequent PTX application [pharmacological manipulation: $\left.F_{(2}, 16\right)=8.756$, $p=0.0027$; depolarization steps: $F_{(4,32)}=25.89, p<0.001$; interaction: $\left.F_{(8}, 64\right)=2.937, p=0.0074, n=9$ neurons $/ 5$ mice; Figures 7D,E]. By contrast, THIP markedly decreased the spike number in Thyl- PNs from control mice [pharmacological manipulation: $F_{(2,20)}=9.191, p=0.0015$; depolarization steps: $\left.F_{(4}, 40\right)=43.65, p<0.001$; interaction: $\left.F_{(8}, 80\right)=4.305$, $p<0.001, n=11$ neurons $/ 5$ mice; Figures 7G,H], but had no effect in those from CSDS mice [pharmacological manipulation: $\left.F_{(2}, 18\right)=1.120, p=0.3479$; depolarization steps: $\left.F_{(4}, 36\right)=60.93, p<0.001$; interaction: $\left.F_{(8}, 72\right)=0.2762$, $p=0.9718, n=10$ neurons $/ 5$ mice; Figures 7J,K]. On the other hand, when we measured the THIP effect on the slopes of fitted curves plotting the spike number against the current strength, similar results were observed. THIP had little effect on the slope in Thy1+ cells from control mice $\left[F_{(2}, 20\right)=2.835, p=0.0824$; Figure $\left.7 \mathrm{C}\right]$ but decreased it in those from CSDS mice $\left[F_{(2,16)}=6.641, p=0.0079\right.$; Figure 7F]. By contrast, for Thy1- cells, THIP decreased the slope from control mice $\left[F_{(2,20)}=9.686, p=0.0011\right.$; Figure 7I $]$ while effected little in CSDS mice $\left[F_{(2}, 18\right)=0.0832$, $p=0.9206$; Figure 7L].

We also used an alternative approach to elicit neuronal firing by injecting a ramped current $(0-250 \mathrm{pA}, 1 \mathrm{~s})$ into the recorded cells. One-way ANOVA revealed that the effects of THIP on the spike number in the two populations from control and CSDS mice were in good accordance with the effects observed when current pulses were used [Thyl+ neurons from control mice, $F_{(2,20)}=3.023, p=0.0712$; Supplementary Figures S4A,B; 


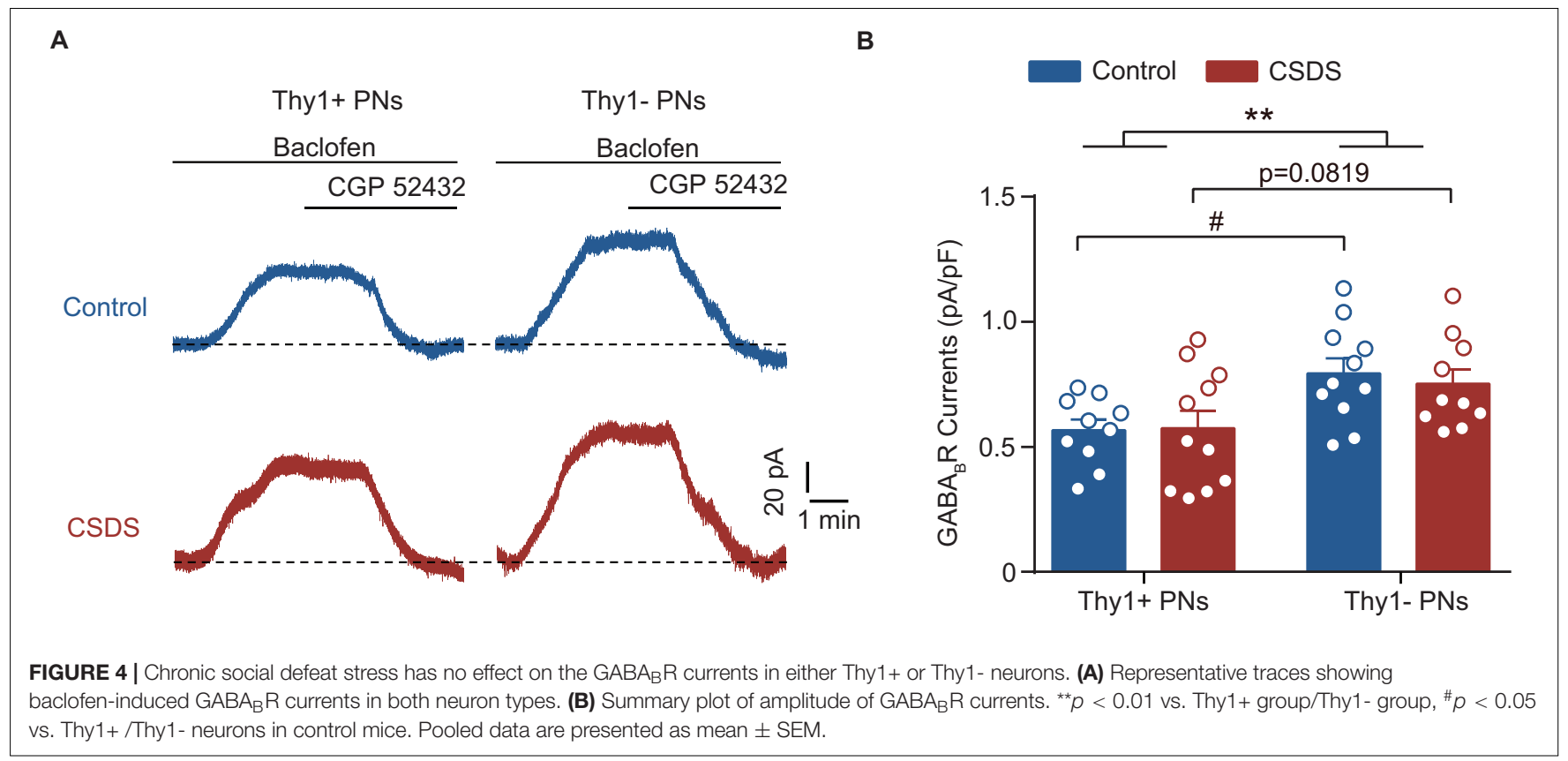

A

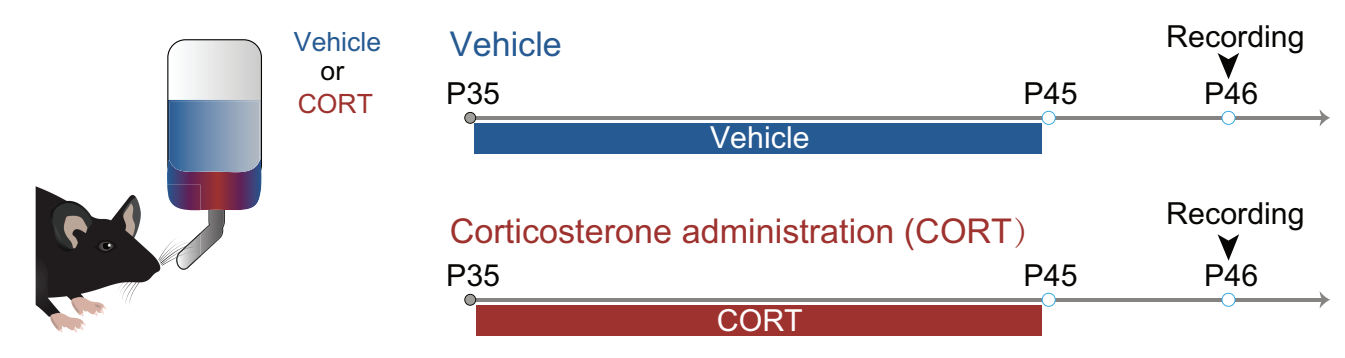

B
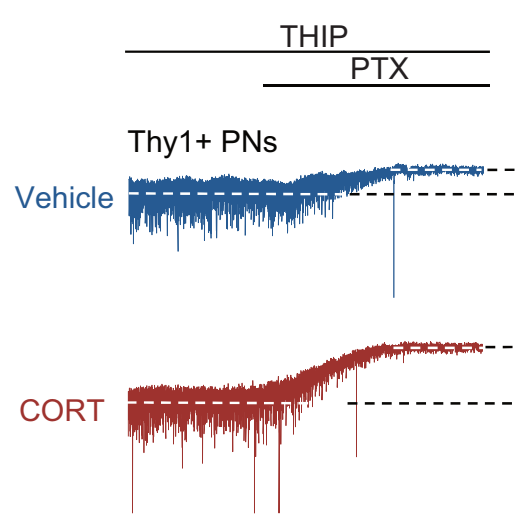

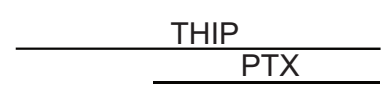

Thy1- PNs

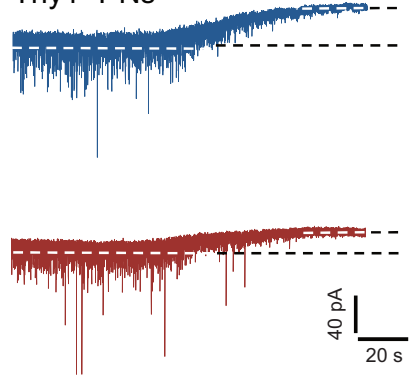

C

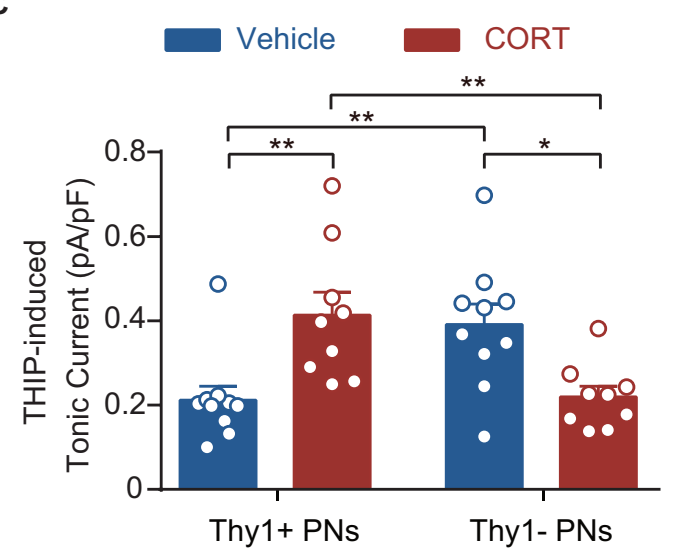

FIGURE $\mathbf{5}$ | Chronic corticosterone administration mimics the effect of CSDS on tonic inhibition in Thy 1+ and Thy 1- neurons in BLA. (A) Schematic showing procedures for vehicle mice and chronic corticosterone administration (CORT) mice. (B) Representative traces of THIP-induced GABA $R$ currents of Thy $1+$ and Thy1- neurons from vehicle- and CORT-treated mice. (C) Average of THIP-induced GABA $A_{A}$ currents in Thy $1+$ and Thy 1 - neurons. ${ }^{*} p<0.05,{ }^{* *} p<0.01$. Pooled data are presented as mean \pm SEM. 
A
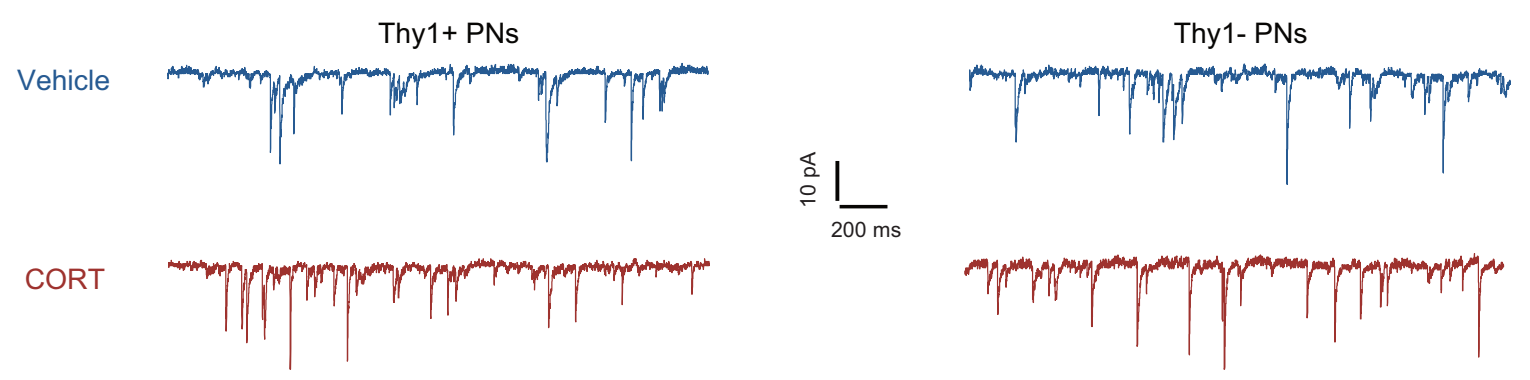

B

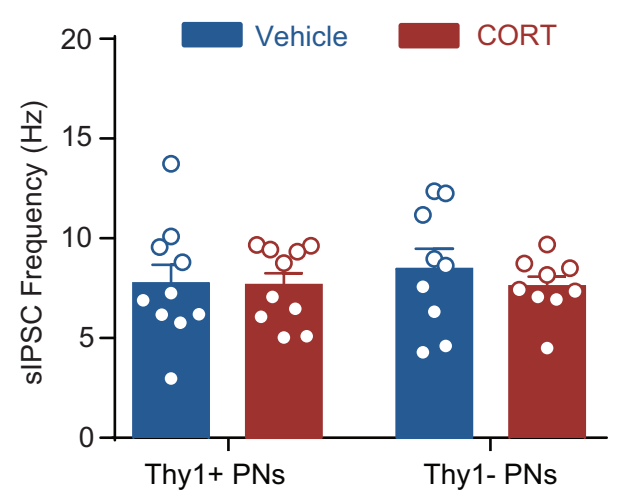

C

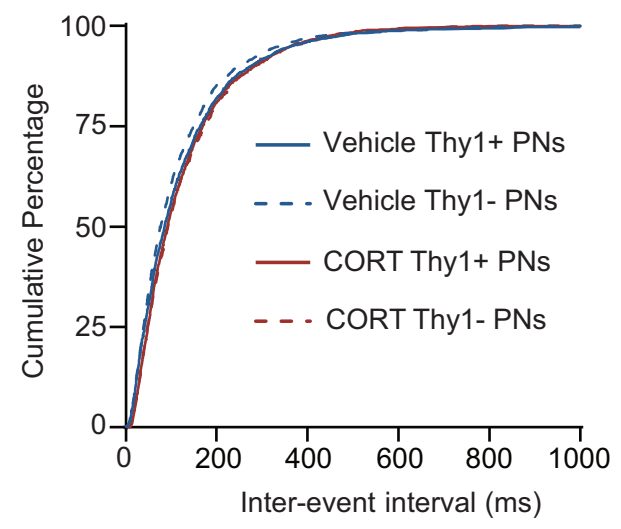

D

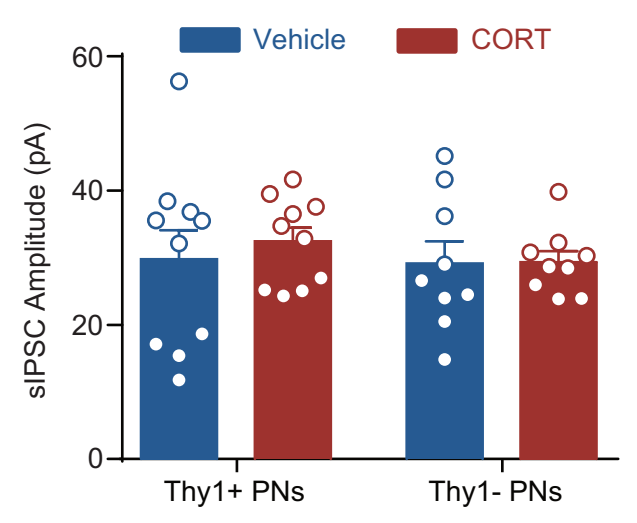

E

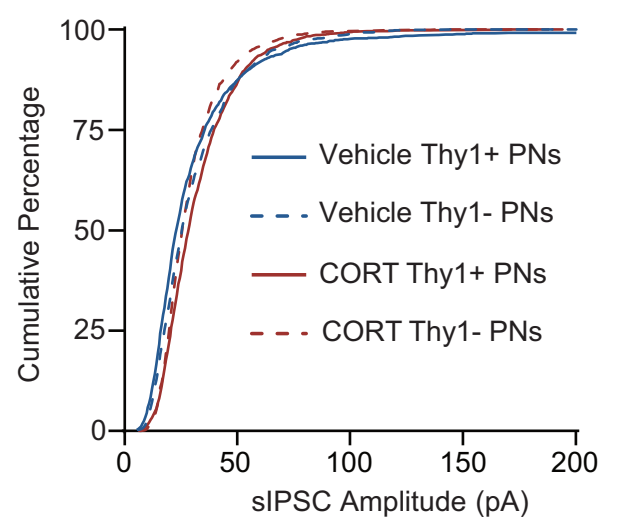

FIGURE 6 | Chronic corticosterone administration has no effect on the phasic inhibition in Thy1+ and Thy1- neurons. (A) Representative traces of spontaneous inhibitory postsynaptic current (SIPSC) in Thy1+ and Thy1- neurons from vehicle and CORT mice. (B) Average of sIPSC frequency. (C) Cumulative probability of interevent interval of SIPSC. (D) Average of sIPSC amplitude. (E) Cumulative probability of amplitude of sIPSC.

Thy1+ neurons from CSDS mice, $F_{(2,16)}=7.825, p=0.0043$; Supplementary Figures S4C,D; Thy1- neurons from control mice, $F_{(2,20)}=10.40$, $p<0.001$; Supplementary Figures S4E,F; Thy1- neurons from CSDS mice, $\left.F_{(2}, 18\right)=2.331, p=0.1258$; Supplementary Figures S4G,H].

Altogether, these findings strongly suggest that under physiological conditions the tonic $\mathrm{GABA}_{\mathrm{A}} \mathrm{R}$ currents differently affect the activity of Thy1+ vs. Thy1- PNs in BLA. Chronic social defeat stress, on the other hand, oppositely affects the effects of tonic GABAergic currents in the two populations.

\section{DISCUSSION}

Here, we showed that CSDS drastically increased the tonic $\mathrm{GABA}_{\mathrm{A}} \mathrm{R}$ currents in Thy1+ neurons, but decreased the currents in Thy1- ones in BLA. It had no effect on the phasic $\mathrm{GABA}_{\mathrm{A}} \mathrm{R}$ currents or $\mathrm{GABA}_{\mathrm{B}} \mathrm{R}$ currents in both populations. Consequently, the GABAergic suppression of neuronal excitability in Thy1+ and in Thy1- neurons was augmented and removed by CSDS, respectively. The opposite regulation of CSDS on the tonic currents in these two populations could be readily mimicked by chronic CORT administration. 


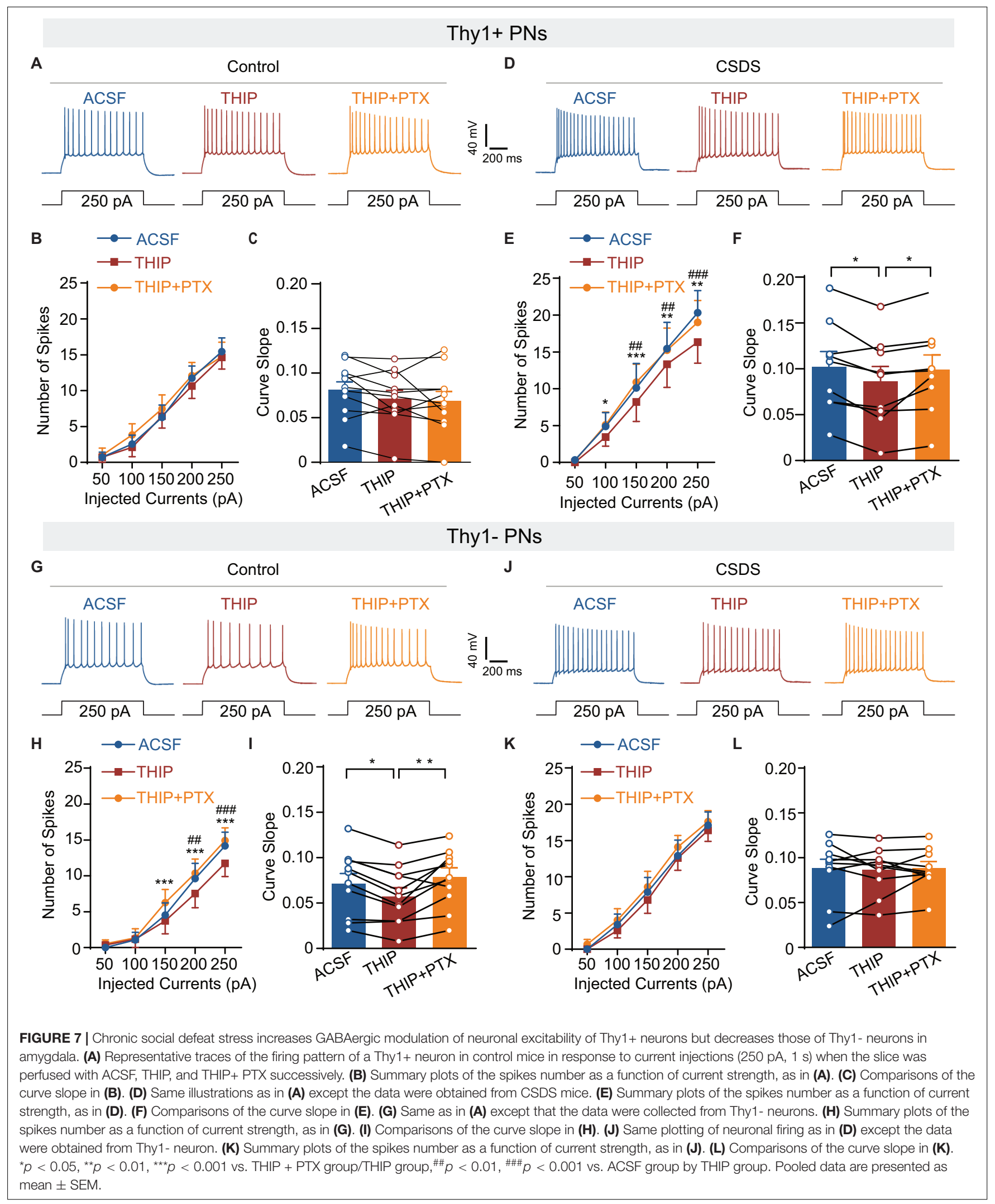


Tonic inhibition, which is mediated by extrasynaptically located $\mathrm{GABA}_{\mathrm{A}} \mathrm{Rs}$, has been extensively observed in many brain regions including cerebellum, hippocampus, amygdala, and neocortex (Brickley and Mody, 2012). Accumulating evidence indicates that the tonic inhibition in amygdala plays a key role in the inhibitory control of amygdala activity (Marowsky et al., 2012; Martin et al., 2014; Liu et al., 2017; Meis et al., 2018). Surprisingly, our results showed that the expression of tonic inhibition in BLA PNs varied drastically with the presence or absence of Thyl, and the tonic $\mathrm{GABA}_{\mathrm{A}} \mathrm{R}$ currents in Thy1+ neurons were far lower than those in Thy1- PNs under normal physiological conditions (control mice). Two possible explanations may underlie this. One is that the tonic inhibition of these two groups of PNs in the amygdala is independent of Thyl expression. The expression pattern of $\mathrm{GABA}_{\mathrm{A}}$ Rs-mediated tonic currents is coincidently overlapped with that of Thy1. Notably, it has been reported that the nucleus accumbens (NAc) and central medial amygdala projectors within the BLA may differentially express tonic inhibition. For example, the NAc projecting neurons express much less Gabrd mRNA, which encodes $\delta$ subunit of $\mathrm{GABA}_{\mathrm{A}}$ Rs that mediates tonic inhibition, than the CeM projecting ones (Namburi et al., 2015). The BLA Thy1+ neurons were primarily terminated in the NAc (Porrero et al., 2010; McCullough et al., 2016), whereas their axons are rarely found in CeM (McCullough et al., 2016). The other one may be that the Thyl acts in gating the expression of tonic inhibition. Indeed, Nosten-Bertrand et al. (1996) have demonstrated a potential link between Thyl and GABAergic signals in hippocampus. The Thy1 null mice exhibited impaired LTP in dentate gyrus of the hippocampus, and such impairment could be rescued by bicuculline, an antagonist of $\mathrm{GABA}_{\mathrm{A}} \mathrm{R}$ (Nosten-Bertrand et al., 1996). However, because many subunits of $\mathrm{GABA}_{\mathrm{A}}$ Rs such as $\delta, \alpha 3$, and $\alpha 5$ have been shown to be involved in the tonic inhibition in amygdala (Marowsky et al., 2012; Martin et al., 2014; Liu et al., 2017; Meis et al., 2018), how Thyl affects the expression and function of these subunits remains to be unknowns and awaits further investigation.

Notably, tonic inhibition has been shown to be regulated by chronic stress. For example, our previous work showed that chronic restraint stress reduces tonic inhibition in BLA projection neurons (Liu et al., 2014). However, these results are obtained from the BLA PNs as a whole, whether the tonic inhibition in individual BLA PNs is differentially regulated by chronic stress remains unknown. Here we observed that CSDS up- and down-regulated the tonic inhibitory currents in Thy1+ and Thy1- neurons, respectively, suggesting the tonic inhibition in the two populations is differentially regulated by CSDS. This may result from the fact that CSDS induces different alteration of the expression of $\mathrm{GABA}_{\mathrm{A}}$ Rs subunits that mediates tonic inhibition in Thyl+/Thy1- neurons. Of note, it has been documented that chronic stress can specifically alter the expressions of distinct $\mathrm{GABA}_{\mathrm{A}} \mathrm{R}$ subunits even in the same brain area (Gunn et al., 2011; Maguire, 2014). For example, in paraventricular nuclei (PVNs), chronic unpredictable stress decreases the expression of $\delta$ subunit but increases that of $\alpha 5$ subunit, whereas it has no effect on $\alpha 3$ subunit expression (Verkuyl et al., 2004). These subunits-containing GABA Rs have been reported in helping with formatting tonic inhibition in amygdala. However, which subunit(s) is (are) responsible for mediating CSDS-induced changes of tonic inhibition in these two neuronal populations needs to be further identified.

In sharp contrast to the tonic inhibition, the phasic inhibition

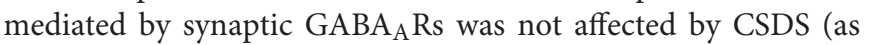
indicated by no changes in the amplitude, frequency, and kinetics of sIPSCs) in both Thy1+ and Thy1- neurons. These results appear to be consistent with previous studies that continuous stress exposure had little influence on phasic inhibition in BLA PNs. Jiang et al. (2009) reported that 3 consecutive days of immobilization and tail shock stress did not affect sIPSCs in amygdala. Moreover, Liu et al. (2014) also demonstrated that the sIPSC in LA PNs remained unaltered after 10 days of chronic restraint stress or chronic unpredictable stress. Not only this, we also found that the $\mathrm{GABA}_{\mathrm{B}} \mathrm{R}$ currents, another important inhibitory current contributing to the inhibition in amygdala (Pan et al., 2009), are not changed after CSDS. However, studies also revealed that chronic stress exposure enables $G_{A B A} R$ internalization to down-regulate $\mathrm{GABA}_{\mathrm{B}} \mathrm{R}$ current in lateral habenula (Lecca et al., 2016) and PVN (Gao et al., 2017), suggesting a possibility that chronic stress may have distinct impacts on the $\mathrm{GABA}_{\mathrm{B}} \mathrm{R}$ currents in different brain regions.

A large number of studies have shown that chronic stress mediates its negative effects through elevating CORT levels (Herman, 2013; Sapolsky, 2015). In accordance with this, we showed that chronic feeding with CORT also mimicked the effect of CSDS on the tonic $\mathrm{GABA}_{\mathrm{A}} \mathrm{R}$ currents in distinct neuron populations, implying that CORT may participate in CSDSinduced differential regulation of $\mathrm{GABA}_{B} \mathrm{R}$ currents. However, how CORT differentially regulates the tonic $\mathrm{GABA}_{\mathrm{A}} \mathrm{R}$ currents in Thy1+ and Thy1- neurons remains elusive. Our previous study has demonstrated that chronic restraint stress reduces the tonic inhibition in BLA PNs as consequence of activation of glucocorticoid receptor (GR), which indicates a pivotal role of GR in modulating tonic inhibition in amygdala (Liu et al., 2014). Indeed, not all PNs in amygdala express GR, and the function of GR varies in different types of neurons (Groeneweg et al., 2011; Gunduz-Cinar et al., 2019). Thus, it is likely that the heterogeneity of the expression and functionality of GR in amygdala may contribute to the differential regulation of tonic inhibition in Thy1+ and Thy1- neurons. Moreover, accumulating evidence reveals that chronic CORT exposure has diverse effects on different subunits of $\mathrm{GABA}_{\mathrm{A}} \mathrm{R}$ (Orchinik et al., 1995, 2001; Cullinan and Wolfe, 2000). The unique receptor composition of $\mathrm{GABA}_{\mathrm{A}} \mathrm{R}$ in distinct BLA PNs may also account for the differential regulation of $\mathrm{GABA}_{\mathrm{A}} \mathrm{R}$-mediated tonic inhibition by CORT. On the other hand, the secretion of many kinds of neurosteroids, such as allopregnanolone (THP), can be elevated by stress (Gunn et al., 2011). These neurosteroids can directly interact with and modulate membrane receptors, such as the $\mathrm{GABA}_{\mathrm{B}} \mathrm{R}$ (Reddy and Estes, 2016; Olsen, 2018). For example, the fluctuation of THP has been implicated in altering the potency and expression of extrasynaptic located $\mathrm{GABA}_{\mathrm{A}} \mathrm{Rs}$, especially the $\delta$ subunit-containing $\mathrm{GABA}_{\mathrm{A}} \mathrm{Rs}$ (Maguire, 2014). In the hippocampal CA1 region of female rodents, a relative short-term (48 h) THP administration caused 
an elevated expression of $\delta$ subunit of $\mathrm{GABA}_{\mathrm{A}} \mathrm{Rs}$, and increased THIP induced tonic currents consequently (Shen et al., 2005). Nevertheless, prolonged THP exposure in pubertal female mice blocked the expression of $\mathrm{GABA}_{\mathrm{A}}$ Rs at a composition of $\alpha 4 \beta 2 \delta$ (Shen et al., 2007). Moreover, THP functions oppositely on tonic inhibition in different compositions of $\mathrm{GABA}_{\mathrm{A}} \mathrm{Rs}$; it decreases outward current of $\alpha 4 \beta 2 \delta \mathrm{GABA}_{\mathrm{A}}$ Rs and increases that of $\alpha 4 \beta 2 \gamma 2, \alpha 4 \beta 3 \delta, \alpha 4 \beta 2$, and $\alpha 1 \beta 2 \delta \mathrm{GABA}_{\mathrm{A}} \mathrm{Rs}$, whereas it has no effect on $\alpha 5 \beta 2 / 3 \gamma \mathrm{GABA}_{\mathrm{A}}$ Rs (Shen et al., 2007), suggesting a paradoxical role of THP in affecting tonic inhibition. On this account, THP may serve on the differential modulation of the tonic inhibition in Thyl+ and Thy1- neurons in the BLA by chronic stress.

Persistent and excessive activation of amygdala following chronic stress contributes to the pathogenesis of stress-related mental disorders (McLaughlin et al., 2009). Consistent with the different changes of tonic inhibition in Thyl+ and Thy1- neurons, we found that CSDS augmented GABAergic suppression of neuronal excitability in Thy1+ neurons but impaired that in Thy1-neurons. Considering the charge transfer mediated by extrasynaptic $\mathrm{GABA}_{\mathrm{A}} \mathrm{R}$ is substantially larger than that of synaptic $\mathrm{GABA}_{\mathrm{A}} \mathrm{R}$ (Botta et al., 2015) and the phasic inhibition in both neuron populations remains unaltered subsequent to CSDS, the altered GABAergic suppression of neuronal excitability is most likely mediated by tonic inhibition. Previous studies have shown that activation of Thy1+ neurons in BLA ("fear-off" neurons) inhibits fear expression and promotes fear extinction (Jasnow et al., 2013; McCullough et al., 2016). Notably, the Thy1- ones are also activated during fear retrieval (McCullough et al., 2016). We speculate that CSDS increased the neuronal excitability in Thy1+ BLA neurons but reduced that of Thy1- neurons, which is potential to cause excessive fear. However, optogenetically activating Thyl+ neurons had little anxiogenic effects (Jasnow et al., 2013). This seems inconsistent with our findings; one possible explanation could be that stress-induced anxiety-like behavior may be mediated by Thy1- neurons rather than Thy1+ ones, or these two neuron groups work synergistically. Actually, the function of Thy1+ and Thy1- neurons is closely related to their projection patterns. As we discussed earlier, Thy $1+$ cells in BLA were reported as preferentially projecting to the brain area where positive valence is mediated such as NAc and bed nucleus of the stria terminalis (McCullough et al., 2016); the increased suppression of Thy1+ neurons by $\mathrm{GABA}_{\mathrm{A}}$ Rs following CSDS may actively contribute to its negative influences on emotion and behavior. On the other hand, Thy1+ neurons rarely project to the CeM (probably Thy1-neurons) (Jasnow et al., 2013), and activation of BLA PNs projecting to CeM contributes to aversive behaviors (Namburi et al., 2015). Moreover, BLA neurons projecting to ventral hippocampus are dramatically activated by chronic stress and are responsible for stress-induced increase of anxiety-like behavior (Zhang J.Y. et al., 2019; Zhang W.H. et al., 2019). Thus, the decreased suppression of Thyl- neurons by $\mathrm{GABA}_{\mathrm{A}} \mathrm{Rs}$ following CSDS may also participate in stress-related psychiatric diseases, while the exact neuron type needs to be identified in future study.
Taken together, our results show that CSDS differentially regulates the tonic $\mathrm{GABA}_{\mathrm{A}} \mathrm{R}$ currents in Thy1+ and Thy1neurons in BLA. In parallel with this finding, the GABAergic control over neuronal firing is also oppositely modulated by CSDS. Despite this, several important questions remain open. For example, what are the specific molecular mechanisms underlying such differential regulation? What is the functional role of the divergent modulation of tonic inhibition in stress-related emotional disorders? Addressing these issues will help to expand our understanding of the molecular and circuit mechanisms of the stress-mediated amygdala disinhibition and provide potential targets for prevention and treatment of stress-related disorders.

\section{DATA AVAILABILITY STATEMENT}

The raw data supporting the conclusions of this article will be made available by the authors, without undue reservation, to any qualified researcher.

\section{ETHICS STATEMENT}

The animal study was reviewed and approved by the Institutional Animal Care and Use Committee of Nanchang University.

\section{AUTHOR CONTRIBUTIONS}

$\mathrm{B}-\mathrm{XP}$ and $\mathrm{W}-\mathrm{HZ}$ conceived and designed the project. $\mathrm{H}-\mathrm{QP}$, $\mathrm{W}-\mathrm{HZ}$, and $\mathrm{C}-\mathrm{ZL}$ performed most experiments and analysis of electrophysiology data. YH performed immunofluorescence experiments. Z-MX, XQ, and $\mathrm{W}$-ZL made the mice models of chronic social defeat and chronic CORT administration. NW, $\mathrm{J}-\mathrm{XZ}$, and X-XL performed behavior test. B-XP, H-QP, and $\mathrm{W}-\mathrm{HZ}$ wrote the manuscript. All authors read and approved the final manuscript.

\section{FUNDING}

This work was supported by grants from National Natural Science Foundation of China (Grant Nos. 81930032, 31970953, 81771459, and 81601179) and Natural Science Foundation of Jiangxi Province (Grant Nos. 20172BCB22005, 20192ACB21024, and 20192ACB20023).

\section{ACKNOWLEDGMENTS}

We thank Dr. Lin Mei (Department of Neurosciences, School of Medicine, Case Western Reserve University) for providing the Thy1-YFP transgenic mice.

\section{SUPPLEMENTARY MATERIAL}

The Supplementary Material for this article can be found online at: https://www.frontiersin.org/articles/10.3389/fnins.2020. 00299/full\#supplementary-material 
FIGURE S1 | There's no differences on the entries to the closed arms of EPM and locomotor activity between control and CSDS mice. (A) Closed arms entries. (B) Total distance traveled during OFT. (C) Total distance traveled in EPM.

FIGURE S2 | No significant differences on rise time and decay time of sIPSCs by CSDS. (A) Average of SIPSC rise time. (B) Cumulative probability of rise time of sIPSC. (C) Average of sIPSC decay time. (D) Cumulative probability of decay time of SIPSC.

FIGURE S3 | No significant differences on rise time and decay time of sIPSCs by CORT administration. (A) Average of sIPSC rise time. (B) Cumulative probability of

\section{REFERENCES}

Bohnsack, J. P., Hughes, B. A., O’Buckley, T. K., Edokpolor, K., Besheer, J., and Morrow, A. L. (2018). Histone deacetylases mediate GABA A receptor expression, physiology, and behavioral maladaptations in rat models of alcohol dependence. Neuropsychopharmacology 43, 1518-1529. doi: 10.1038/s41386018-0034-8

Botta, P., Demmou, L., Kasugai, Y., Markovic, M., Xu, C., Fadok, J. P., et al. (2015). Regulating anxiety with extrasynaptic inhibition. Nat. Neurosci. 18, 1493-1500. doi: $10.1038 / \mathrm{nn} .4102$

Brambilla, P., Perez, J., Barale, F., Schettini, G., and Soares, J. C. (2003). GABAergic dysfunction in mood disorders. Mol. Psychiatry 8:721. doi: 10.1038/ sj.mp. 4001362

Brickley, S. G., and Mody, I. (2012). Extrasynaptic GABAA receptors: their function in the CNS and implications for disease. Neuron 73, 23-34. doi: 10. 1016/j.neuron.2011.12.012

Cullinan, W. E., and Wolfe, T. J. (2000). Chronic stress regulates levels of mRNA transcripts encoding $\beta$ subunits of the GABAA receptor in the rat stress axis. Brain Res. 887, 118-124. doi: 10.1016/S0006-8993(00)03000-6

de Kloet, E. R., Joëls, M., and Holsboer, F. (2005). Stress and the brain: from adaptation to disease. Nat. Rev. Neurosci. 6, 463-475. doi: 10.1038/nrn 1683

Gao, Y., Zhou, J.-J., Zhu, Y., Wang, L., Kosten, T. A., Zhang, X., et al. (2017). Neuroadaptations of presynaptic and postsynaptic GABAB receptor function in the paraventricular nucleus in response to chronic unpredictable stress. $B r . J$. Pharmacol. 174, 2929-2940. doi: 10.1111/bph.13924

Gilman, T. L., Dutta, S., Adkins, J. M., Cecil, C. A., and Jasnow, A. M. (2018). Basolateral amygdala Thyl-expressing neurons facilitate the inhibition of contextual fear during consolidation, reconsolidation, and extinction. Neurobiol. Learn. Mem. 155, 498-507. doi: 10.1016/j.nlm.2018.09.010

Golden, S. A., Covington, H. E., Berton, O., and Russo, S. J. (2011). A standardized protocol for repeated social defeat stress in mice. Nat. Protoc. 6, 1183-1191. doi: 10.1038/nprot.2011.361

Groeneweg, F. L., Karst, H., De, E. K., and Joëls, M. (2011). Rapid nongenomic effects of corticosteroids and their role in the central stress response. J. Endocrinol. 209, 153-167. doi: 10.1530/JOE-10-0472

Gunduz-Cinar, O., Brockway, E., Lederle, L., Wilcox, T., Halladay, L. R., Ding, Y., et al. (2019). Identification of a novel gene regulating amygdalamediated fear extinction. Mol. Psychiatry 24, 601-612. doi: 10.1038/s41380-0170003-3

Gunn, B. G., Brown, A. R., Lambert, J. J., and Belelli, D. (2011). Neurosteroids and GABAA receptor interactions: a focus on stress. Front. Neurosci. 5:131. doi: 10.3389/fnins.2011.00131

Herman, J. (2013). Neural control of chronic stress adaptation. Front. Behav. Neurosci. 7:61. doi: 10.3389/fnbeh.2013.00061

Janak, P. H., and Tye, K. M. (2015). From circuits to behaviour in the amygdala. Nature 517, 284-292. doi: 10.1038/nature14188

Jasnow, A. M., Ehrlich, D. E., Choi, D. C., Dabrowska, J., Bowers, M. E., McCullough, K. M., et al. (2013). Thyl-expressing neurons in the basolateral amygdala may mediate fear inhibition. J. Neurosci. 33, 10396-10404. doi: 10. 1523/JNEUROSCI.5539-12.2013

Jiang, X., Xing, G., Yang, C., Verma, A., Zhang, L., and Li, H. (2009). Stress impairs 5-HT2A receptor-mediated serotonergic facilitation of GABA release in juvenile rat basolateral amygdala. Neuropsychopharmacology 34, 410-423. doi: $10.1038 /$ npp. 2008.71 rise time of sIPSC. (C) Average of sIPSC decay time. (D) Cumulative probability of decay time of SIPSC.

FIGURE S4 | CSDS differentially modulates tonic inhibitory control over neural firing of Thy $1+$ and Thy 1 - neurons in amygdala. (A,C) Representative traces of the firing pattern of Thy1+ neurons from control (A) and CSDS mice (C) in response to a ramp current injection (0-250 pA, 1 s). (B,D) Summary plots of the spike number in $(\mathbf{A})$ and $\mathbf{( C )}$, respectively. $(\mathbf{E}, \mathbf{G})$ Representative traces of the firing pattern of Thy1- neurons from control (E) and CSDS mice (G). (F,H) Summary plots of the spike number in $(\mathbf{E}, \mathbf{G})$, respectively. ${ }^{\star} p<0.05,{ }^{\star \star} p<0.01$, ${ }^{\star * \star} p<0.001$. Pooled data are presented as mean \pm SEM.

Jie, F., Yin, G., Yang, W., Yang, M., Gao, S., Lv, J., et al. (2018). Stress in regulation of GABA amygdala system and relevance to neuropsychiatric diseases. Front. Neurosci. 12:562. doi: 10.3389/fnins.2018.00562

Jin, L., Hu, P., Wang, Y., Wu, L., Qin, K., Cheng, H., et al. (2020). Fast-acting black-phosphorus-assisted depression therapy with low toxicity. Adv. Mater. 32:1906050. doi: 10.1002/adma.201906050

Kim, J., Pignatelli, M., Xu, S., Itohara, S., and Tonegawa, S. (2016). Antagonistic negative and positive neurons of the basolateral amygdala. Nat. Neurosci. 19, 1636-1646. doi: 10.1038/nn.4414

Lecca, S., Pelosi, A., Tchenio, A., Moutkine, I., Lujan, R., Hervé, D., et al. (2016). Rescue of GABAB and GIRK function in the lateral habenula by protein phosphatase 2A inhibition ameliorates depression-like phenotypes in mice. Nat. Med. 22, 254-261. doi: 10.1038/nm.4037

LeDoux, J. (2007). The amygdala. Curr. Biol. 17, R868-R874. doi: 10.1016/j.cub. 2007.08.005

Liu, Z.-P., He, Q.-H., Pan, H.-Q., Xu, X.-B., Chen, W.-B., He, Y., et al. (2017). Delta subunit-containing gamma-aminobutyric acid a receptor disinhibits lateral amygdala and facilitates fear expression in mice. Biol. Psychiatry 81, 990-1002. doi: 10.1016/j.biopsych.2016.06.022

Liu, Z.-P., Song, C., Wang, M., He, Y., Xu, X.-B., Pan, H.-Q., et al. (2014). Chronic stress impairs GABAergic control of amygdala through suppressing the tonic GABAA receptor currents. Mol. Brain 7:32. doi: 10.1186/1756-6606-7-32

Maguire, J. (2014). Stress-induced plasticity of GABAergic inhibition. Front. Cell. Neurosci. 8:157. doi: 10.3389/fncel.2014.00157

Manzanares, P. A. R., Isoardi, N. A., Carrer, H. F., and Molina, V. A. (2005). Previous stress facilitates fear memory, attenuates GABAergic inhibition, and increases synaptic plasticity in the rat basolateral amygdala. J. Neurosci. 25, 8725-8734. doi: 10.1523/JNEUROSCI.2260-05.2005

Marowsky, A., Rudolph, U., Fritschy, J.-M., and Arand, M. (2012). Tonic inhibition in principal cells of the amygdala: a central role for $\alpha 3$ subunit-containing GABAA receptors. J. Neurosci. 32, 8611-8619. doi: 10.1523/JNEUROSCI.440411.2012

Martin, B. S., Corbin, J. G., and Huntsman, M. M. (2014). Deficient tonic GABAergic conductance and synaptic balance in the fragile $\mathrm{X}$ syndrome amygdala. J Neurophysiol. 112, 890-902. doi: 10.1152/jn.00597.2013

McCullough, K. M., Choi, D., Guo, J., Zimmerman, K., Walton, J., Rainnie, D. G., et al. (2016). Molecular characterization of Thyl expressing fear-inhi-biting neurons within the basolateral amygdala. Nat. Commun. 7:13149. doi: 10.1038/ ncomms13149

McEwen, B. S. (2007). Physiology and neurobiology of stress and adaptation: central role of the brain. Physiol. Rev. 87, 873-904. doi: 10.1152/physrev.00041. 2006

McLaughlin, K. J., Baran, S. E., and Conrad, C. D. (2009). Chronic stress- and sexspecific neuromorphological and functional changes in limbic structures. Mol. Neurobiol. 40, 166-182. doi: 10.1007/s12035-009-8079-7

Meis, S., Endres, T., Munsch, T., and Lessmann, V. (2018). Presynaptic regulation of tonic inhibition by neuromodulatory transmitters in the basal amygdala. Mol. Neurobiol. 55, 8509-8521. doi: 10.1007/s12035-018-0984-1

Moda-Sava, R. N., Murdock, M. H., Parekh, P. K., Fetcho, R. N., Huang, B. S., Huynh, T. N., et al. (2019). Sustained rescue of prefrontal circuit dysf-unction by antidepressant-induced spine formation. Science 364:eaat8078. doi: 10.1126/ science.aat 8078

Namburi, P., Beyeler, A., Yorozu, S., Calhoon, G. G., Halbert, S. A., Wichmann, R., et al. (2015). A circuit mechanism for differentiating positive and negative associations. Nature 520, 675-678. doi: 10.1038/nature14366 
Nosten-Bertrand, M., Errington, M. L., Murphy, K. P. S. J., Tokugawa, Y., Barboni, E., Kozlova, E., et al. (1996). Normal spatial learning despite regional inhibition of LTP in mice lacking Thy-1. Nature 379:826. doi: 10.1038/379826a0

Nuss, P. (2015). Anxiety disorders and GABA neurotransmission: a disturbance of modulation. Neuropsychiatr. Dis. Treat. 11, 165-175. doi: 10.2147/NDT.S58841

Olsen, R. W. (2018). GABAA receptor: positive and negative allosteric modulators. Neuropharmacology 136, 10-22. doi: 10.1016/j.neuropharm.2018.01.036

Orchinik, M., Carroll, S. S., Li, Y.-H., McEwen, B. S., and Weiland, N. G. (2001). Heterogeneity of hippocampal GABAA receptors: regulation by corticosterone. J. Neurosci. 21, 330-339. doi: 10.1523/JNEUROSCI.21-01-00330.2001

Orchinik, M., Weiland, N. G., and McEwen, B. S. (1995). Chronic exposure to stress levels of corticosterone alters GABAA receptor subunit mRNA levels in rat hippocampus. Brain Res. Mol. Brain Res. 34, 29-37. doi: 10.1016/0169-328X(95) 00118-C

Pan, B.-X., Dong, Y., Ito, W., Yanagawa, Y., Shigemoto, R., and Morozov, A. (2009). Selective gating of glutamatergic inputs to excitatory neurons of amygdala by presynaptic GABAb receptor. Neuron 61, 917-929. doi: 10.1016/j.neuron.2009. 01.029

Porrero, C., Rubio-Garrido, P., Avendaño, C., and Clascá, F. (2010). Mapping of fluorescent protein-expressing neurons and axon pathways in adult and developing Thy1-eYFP-H transgenic mice. Brain Res. 1345, 59-72. doi: 10.1016/ j.brainres.2010.05.061

Qin, X., He, Y., Wang, N., Zou, J.-X., Zhang, Y.-M., Cao, J.-L., et al. (2019). Moderate maternal separation mitigates the altered synaptic transmission and neuronal activation in amygdala by chronic stress in adult mice. Mol. Brain 12:111. doi: 10.1186/s13041-019-0534-4

Qin, Z., Zhou, X., Pandey, N. R., Vecchiarelli, H. A., Stewart, C. A., Zhang, X., et al. (2015). Chronic stress induces anxiety via an amygdalar intrac-ellular cascade that impairs endocannabinoid signaling. Neuron 85, 1319-1331. doi: 10.1016/j.neuron.2015.02.015

Quirk, G. J., and Gehlert, D. R. (2003). Inhibition of the amygdala: key to pathological states? Ann. N. Y. Acad. Sci. 985, 263-272. doi: 10.1111/j.17496632.2003.tb07087.x

Reddy, D. S., and Estes, W. A. (2016). Clinical potential of neurosteroids for CNS disorders. Trends Pharmacol. Sci. 37, 543-561. doi: 10.1016/j.tips.2016.04.003

Rosenkranz, J. A., Venheim, E. R., and Padival, M. (2010). Chronic stress causes amygdala hyperexcitability in rodents. Biol. Psychiatry 67, 1128-1136. doi: 10. 1016/j.biopsych.2010.02.008

Sapolsky, R. M. (2015). Stress and the brain: individual variability and the invertedU. Nat. Neurosci. 18, 1344-1346. doi: 10.1038/nn.4109

Senn, V., Wolff, S. B. E., Herry, C., Grenier, F., Ehrlich, I., Gründemann, J., et al. (2014). Long-range connectivity defines behavioral specificity of amygdala neurons. Neuron 81, 428-437. doi: 10.1016/j.neuron.2013.11.006

Shen, H., Gong, Q. H., Aoki, C., Yuan, M., Ruderman, Y., Dattilo, M., et al. (2007). Reversal of neurosteroid effects at $\alpha 4 \beta 2 \delta$ GABAA receptors triggers anxiety at puberty. Nat. Neurosci. 10, 469-477. doi: 10.1038/nn1868

Shen, H., Gong, Q. H., Yuan, M., and Smith, S. S. (2005). Short-term steroid treatment increases $\delta$ GABAA receptor subunit expression in rat CA1 hippocampus: pharmacological and behavioral effects. Neuropharmacology 49, 573-586. doi: 10.1016/j.neuropharm.2005.04.026

Song, C., Zhang, W.-H., Wang, X.-H., Zhang, J.-Y., Tian, X.-L., Yin, X.-P., et al. (2017). Acute stress enhances the glutamatergic transmission onto basoamygdala neurons embedded in distinct microcircuits. Mol. Brain 10:3. doi: 10.1186/s13041-016-0283-6

Trujeque-Ramos, S., Castillo-Rolón, D., Galarraga, E., Tapia, D., Arenas-López, G., Mihailescu, S., et al. (2018). Insulin regulates GABAA receptor-med-iated tonic currents in the prefrontal cortex. Front. Neurosci. 12:345. doi: 10.3389/fnins. 2018.00345

Verkuyl, J. M., Hemby, S. E., and Joëls, M. (2004). Chronic stress attenuates GABAergic inhibition and alters gene expression of parvocellular neurons in rat hypothalamus. Eur. J. Neurosci. 20, 1665-1673. doi: 10.1111/j.1460-9568.2004. 03568.x

Vyas, A., Mitra, R., Rao, B. S. S., and Chattarji, S. (2002). Chronic stress induces contrasting patterns of dendritic remodeling in hippocampal and amygdaloid neurons. J. Neurosci. 22, 6810-6818. doi: 10.1523/JNEUROSCI.22-15-06810. 2002

Williams, A. F., and Gagnon, J. (1982). Neuronal cell Thy-1 glycoprotein: homology with immunoglobulin. Science 216, 696-703. doi: 10.1126/science. 6177036

Zhang, J.-Y., Liu, T.-H., He, Y., Pan, H.-Q., Zhang, W.-H., Yin, X.-P., et al. (2019). Chronic stress remodels synapses in an amygdala circuit-specific manner. Biol. Psychiatry 85, 189-201. doi: 10.1016/j.biopsych.2018.06.019

Zhang, W.-H., Liu, W.-Z., He, Y., You, W.-J., Zhang, J.-Y., Xu, H., et al. (2019). Chronic stress causes projection-specific adaptation of amygdala neurons via small-conductance calcium-activated potassium channel downregulation. Biol. Psychiatry 85, 812-828. doi: 10.1016/j.biopsych.2018.12.010

Zhang, X., Ge, T., Yin, G., Cui, R., Zhao, G., and Yang, W. (2018). Stress-induced functional alterations in amygdala: implications for neuropsychiatric diseases. Front. Neurosci. 12:367. doi: 10.3389/fnins.2018.00367

Zhou, H.-Y., He, J.-G., Hu, Z.-L., Xue, S.-G., Xu, J.-F., Cui, Q.-Q., et al. (2019). A-kinase anchoring protein 150-PKA complex in the basolateral amygdala contributes to depressive-like behaviors induced by chronic restraint stress. Biol. Psychiatry 86, 131-142. doi: 10.1016/j.biopsych.2019. 03.967

Conflict of Interest: The authors declare that the research was conducted in the absence of any commercial or financial relationships that could be construed as a potential conflict of interest.

Copyright (c) 2020 Pan, Zhang, Liao, He, Xiao, Qin, Liu, Wang, Zou, Liu and Pan. This is an open-access article distributed under the terms of the Creative Commons Attribution License (CC BY). The use, distribution or reproduction in other forums is permitted, provided the original author(s) and the copyright owner(s) are credited and that the original publication in this journal is cited, in accordance with accepted academic practice. No use, distribution or reproduction is permitted which does not comply with these terms. 